\title{
Hurricane Gustav (2008) Waves and Storm Surge: Hindcast, Synoptic Analysis, and Validation in Southern Louisiana
}

\author{
J. C. Dietrich, ${ }^{\mathrm{a}, \mathrm{j}}$ J. J. Westerink, ${ }^{\mathrm{a}}$ A. B. Kennedy, ${ }^{\mathrm{a}}$ J. M. Smith, ${ }^{\mathrm{b}}$ R. E. Jensen, ${ }^{\mathrm{b}}$ \\ M. Zijlema, ${ }^{\mathrm{c}}$ L. H. Holthuijsen, ${ }^{\mathrm{c}}$ C. Dawson, ${ }^{\mathrm{d}}$ R. A. Luettich JR., ${ }^{\mathrm{e}}$ M. D. Powell, ${ }^{\mathrm{f}}$ \\ V. J. Cardone, ${ }^{\mathrm{g}}$ A. T. Cox,,${ }^{\mathrm{g}}$ G. W. StOne, ${ }^{\mathrm{h}}$ H. POURTAheri, ${ }^{\mathrm{i}}$ M. E. Hope, ${ }^{\mathrm{a}}$ \\ S. TANAKA, ${ }^{\mathrm{a}}$ L. G. WeSTERINK, ${ }^{\mathrm{a}}$ H. J. Westerink, ${ }^{\mathrm{a}}$ AND Z. COBELl ${ }^{\mathrm{a}, \mathrm{k}}$ \\ ${ }^{a}$ Department of Civil Engineering and Geological Sciences, University of Notre Dame, Notre Dame, Indiana \\ ${ }^{\mathrm{b}}$ Coastal and Hydraulics Laboratory, U.S. Army Engineer Research and Development Center, Vicksburg, Mississippi \\ ${ }^{\mathrm{c}}$ Faculty of Civil Engineering and Geosciences, Delft University of Technology, Delft, Netherlands \\ ${ }^{\mathrm{d}}$ Institute for Computational Engineering and Sciences, University of Texas at Austin, Austin, Texas \\ ${ }^{\mathrm{e}}$ Institute of Marine Sciences, University of North Carolina at Chapel Hill, Morehead City, North Carolina \\ ${ }^{\mathrm{f}}$ NOAA/Atlantic Oceanographic and Meteorological Laboratory/Hurricane Research Division, Miami, Florida \\ ${ }^{\mathrm{g}}$ Oceanweather, Inc., Cos Cob, Connecticut \\ ${ }^{\mathrm{h}}$ Coastal Studies Institute, Louisiana State University, Baton Rouge, Louisiana \\ ${ }^{\mathrm{i}}$ New Orleans District, U.S. Army Corps of Engineers, New Orleans, Louisiana
}

(Manuscript received 31 August 2010, in final form 4 March 2011)

\begin{abstract}
Hurricane Gustav (2008) made landfall in southern Louisiana on 1 September 2008 with its eye never closer than $75 \mathrm{~km}$ to New Orleans, but its waves and storm surge threatened to flood the city. Easterly tropicalstorm-strength winds impacted the region east of the Mississippi River for 12-15 h, allowing for early surge to develop up to $3.5 \mathrm{~m}$ there and enter the river and the city's navigation canals. During landfall, winds shifted from easterly to southerly, resulting in late surge development and propagation over more than $70 \mathrm{~km}$ of marshes on the river's west bank, over more than $40 \mathrm{~km}$ of Caernarvon marsh on the east bank, and into Lake Pontchartrain to the north. Wind waves with estimated significant heights of $15 \mathrm{~m}$ developed in the deep Gulf of Mexico but were reduced in size once they reached the continental shelf. The barrier islands further dissipated the waves, and locally generated seas existed behind these effective breaking zones.

The hardening and innovative deployment of gauges since Hurricane Katrina (2005) resulted in a wealth of measured data for Gustav. A total of 39 wind wave time histories, 362 water level time histories, and 82 high water marks were available to describe the event. Computational models-including a structured-mesh deepwater wave model (WAM) and a nearshore steady-state wave (STWAVE) model, as well as an unstructured-mesh "simulating waves nearshore" (SWAN) wave model and an advanced circulation (ADCIRC) model-resolve the region with unprecedented levels of detail, with an unstructured mesh spacing of 100-200 $\mathrm{m}$ in the wave-breaking zones and 20-50 $\mathrm{m}$ in the small-scale channels. Data-assimilated winds were applied using NOAA's Hurricane Research Division Wind Analysis System (H*Wind) and Interactive Objective Kinematic Analysis (IOKA) procedures. Wave and surge computations from these models are validated comprehensively at the measurement locations ranging from the deep Gulf of Mexico and along the coast to the rivers and floodplains of southern Louisiana and are described and quantified within the context of the evolution of the storm.
\end{abstract}

\footnotetext{
${ }^{\mathrm{j}}$ Current affiliation: Institute for Computational Engineering and Sciences, University of Texas at Austin, Austin, Texas.

${ }^{\mathrm{k}}$ Current affiliation: Arcadis, Inc., Denver, Colorado.
}

Corresponding author address: J. C. Dietrich, Institute for Computational Engineering and Sciences, University of Texas at Austin, 1 University Station, C0200, Austin, TX 78712.

E-mail: dietrich@ices.utexas.edu

\section{Introduction}

New Orleans and its infrastructure are surrounded by extensive levees and raised features, marshes to the south and east, and barrier islands on the LouisianaMississippi shelf. Hurricane Katrina (2005) exposed vulnerabilities as it generated storm surge throughout the region, flooding in the city due to breaches along its shipping and drainage canals, and water levels along the 


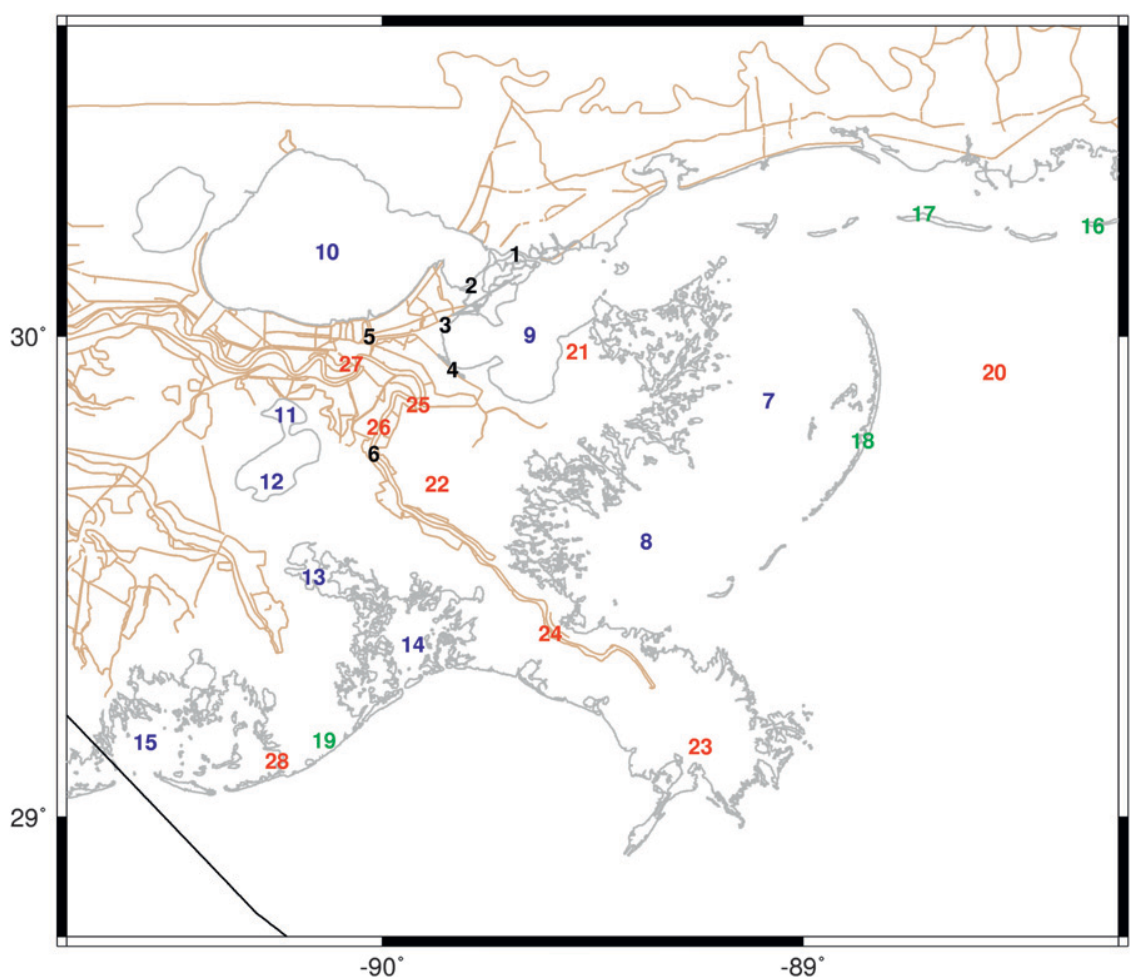

FIG. 1. Schematic of southeastern Louisiana. Solid lines indicate Gustav's track (black), ADCIRC levee/road boundaries (brown), and the coastline (gray). Geographic locations of interest are indicated by numbers identified in Table 1 .

Mississippi coastline that were the largest measured in the United States (Ebersole et al. 2007). But Katrina was an especially large and devastating hurricane. It reached category 5 on the Saffir-Simpson scale in the Gulf of Mexico before weakening to category 3 prior to its first landfall, maintained its intensity through the Breton and Chandeleur Sounds, and tracked near metropolitan New Orleans (Knabb et al. 2005).

Hurricane Gustav (2008) was the first major hurricane to track through southeast Louisiana since Katrina (Fig. 1; Table 1), and it made landfall on 1 September 2008. Gustav was much weaker than Katrina, both in the Gulf and at landfall, it tracked farther west, and its eye was never closer than $75 \mathrm{~km}$ to New Orleans. For those reasons, its waves and surge were expected to be less threatening to the city. However, Gustav increased in size as it approached Louisiana, and its outer, tropical-storm-strength winds impacted the system for 12-15 h. Gustav generated waves that damaged infrastructure in southern Louisiana and offshore, and its surge nearly overtopped large sections of the levee/ floodwall system throughout metropolitan New Orleans.

Measured data for waves and surge are more extensive and detailed than for any previous Gulf hurricane. Measured time series describe wave generation, propagation, and dissipation from the deep Gulf of Mexico onto the continental shelf and into the marshes and coastal floodplains. The National Data Buoy Center (NDBC) collected measurements at its buoys throughout the Gulf, where the depths range to several kilometers and the peak wave heights reached an estimated $15 \mathrm{~m}$. On the shelf, the Coastal Studies Institute (CSI; http://www.wavcis.lsu.edu) collected measurements at five stations west of the Mississippi River delta, where a decrease in bathymetry and wave damping limited the peak wave heights to $3-5 \mathrm{~m}$. Sixteen gauges deployed by Andrew Kennedy (AK) of the University of Notre Dame were located along the coastline from Calcasieu Pass to Pensacola Bay, in depths ranging from 1 to $20 \mathrm{~m}$, and they offer an unprecedented description of the nearshore wave behavior during a major hurricane (Kennedy et al. 2010). Additionally, six gauges deployed by the Coastal Hydraulics Laboratory (CHL) of the U.S. Army Engineer Research and Development Center (USA-ERDC) show the dissipation of waves in the Terrebonne and Biloxi marshes. This level of available wave data was possible because of permanent gauge hardening and the increased deployment of temporary gauges since Katrina.

High-water marks (HWMs) were collected by the Federal Emergency Management Agency (FEMA), while time series of water levels were collected by AK, CHL, the 


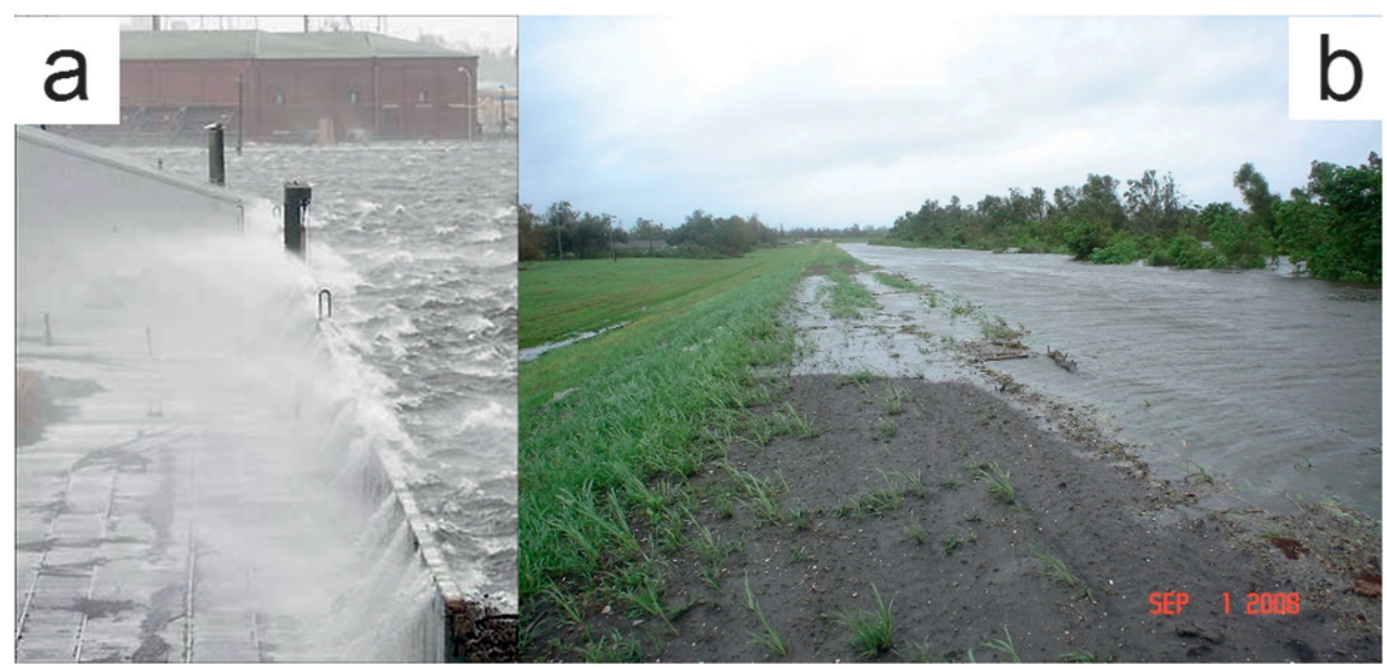

FIG. 2. Photographs during Gustav of (a) waves overtopping the IHNC walls near the Ninth Ward and (b) surge overtopping the earthen levee near Braithwaite. (Courtesy of Nancy Powell, USACE.)

U.S. Army Corps of Engineers (USACE), the U.S. Geological Survey (USGS), the National Oceanic and Atmospheric Administration (NOAA), and the Coastwide Reference Monitoring System (CRMS). These data show how the surge evolved throughout the storm. Water levels are reported relative to the North American Vertical Datum of 1988 (NAVD88) updated to the 2004.65 epoch, unless otherwise noted. Surge of 2.5-3 m was pushed across the shelf and against the levees of lower Plaquemines Parish, which is fronted by a relatively narrow marsh and Breton Sound. The river levees extend farther southward on the west bank, and they helped to capture and steer this surge upriver. Surge accumulated against the levees near the confluence of the Gulf Intracoastal Waterway (GIWW) and the Mississippi River Gulf Outlet (MRGO), where it flowed into the Inner Harbor Navigation Canal (IHNC) and the center of the city, reaching to $3.5 \mathrm{~m}$. There were reports of wave overtopping of the city floodwalls and levees (Fig. 2a), although no breaches occurred. An early setup of $1 \mathrm{~m}$ along the southwest shore of Lake Pontchartrain became $2-2.25 \mathrm{~m}$ after the lake filled. To the east of the river, the surge reached $2.5 \mathrm{~m}$ against the levees near English Turn and Braithwaite (Fig. 2b), which are fronted by $40 \mathrm{~km}$ of Caernarvon marsh that marginally attenuated the water levels. To the west of the river, a surge of 2-2.5 m developed near Port Fourchon and Grand Isle as the storm was making landfall. When the winds shifted, surge was pushed into Terrebonne and Barataria Bays, northward through the interconnected marshes and waterways, and reached $1 \mathrm{~m}$ near the west bank of New Orleans, but not until $12-36 \mathrm{~h}$ after landfall. Thus, despite making landfall more than $75 \mathrm{~km}$ from New Orleans, Gustav created significant surge on all sides of the city.
Because of the complexities of southern Louisiana and its response to hurricane forcing, computational models have been developed that utilize unstructured meshes to resolve at basin, shelf, floodplain, and channel scales (Westerink et al. 2008; Bunya et al. 2010). Mesh resolution varies from kilometers in deep water to tens of meters in the small-scale channels and features inland and near the levee protection system. These meshes incorporate the frictional dissipation due to variability in land cover, local geology, and bottom sediments (Bunya et al. 2010; Sheremet and Stone 2003). Surge is allowed to propagate onto the continental shelf and interact with the complex geometry and land cover nearshore and inland. The advanced circulation (ADCIRC) shallow-water model was validated on the unstructured SL15 mesh for Hurricanes Katrina and Rita (2005), and it showed high levels of model skill for tides, riverine stages, waves, and storm surge (Bunya et al. 2010; Dietrich et al. 2010). The SL15 model was used extensively for design work and analysis by the USACE, FEMA, and local agencies (Ebersole et al. 2007; FEMA 2009a; USACE 2009).

The Gustav hindcast utilizes the latest SL16 mesh, which contains twice the resolution of the SL15 mesh. The Gulf is resolved with a resolution of 4-6 km, and the mesh size decreases accordingly on the shelf to 500-1000 m. In the wave breaking zones and inland, the resolution is never greater than $200 \mathrm{~m}$, to improve the wave breaking and the transfer of wave radiation stress gradients to ADCIRC. In the small-scale channels and passes, such as the Mississippi River and its distributaries, the MRGO, and the Rigolets and Chef Menteur passes, the resolution varies to $20-50 \mathrm{~m}$. Bathymetry and topography were reapplied from the latest sources, as described below. 

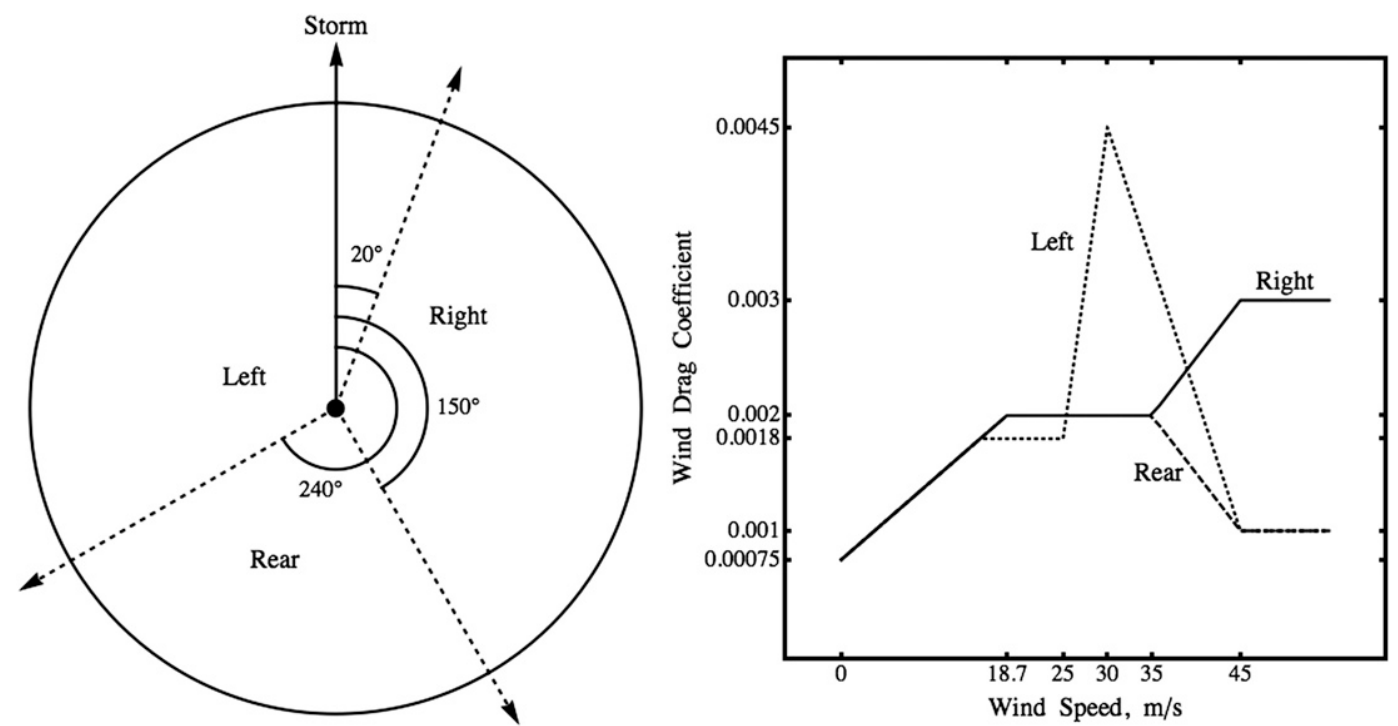

FIG. 3. Schematics of the azimuthal wind drag, showing (left) extents of sectors in relation to direction of storm movement, and (right) wind drag coefficient variability by storm sector, from Powell (2006).

Advancements have also been made in the coupling of wave and circulation models. ADCIRC has been coupled to two structured-mesh wave models: the deepwater wave model (WAM) on a basin scale, and the nearshore steadystate wave (STWAVE) model on regional scales (Komen et al. 1994; Smith 2000; Smith et al. 2001; Günther 2005; Bunya et al. 2010; Dietrich et al. 2010). The spectral wave energy from WAM was interpolated and used as boundary conditions for five nearshore STWAVE meshes, four of which allowed waves to propagate only in the half plane directed onshore. Now STWAVE has been applied with full-plane propagation in all nearshore meshes. Alternatively, ADCIRC has been coupled with the unstructuredmesh version of the "simulating waves nearshore" (SWAN) model (SiadatMousavi et al. 2009; Zijlema 2010). The model herein called SWAN+ADCIRC employs the same unstructured mesh on the same computational cores, passing information between models through local memory/cache, and thus it can simulate the propagation of waves from deep water to the nearshore with accuracy and efficiency (Dietrich et al. 2011).

These new models are well positioned to simulate hurricanes in southern Louisiana, and Gustav is an appropriate validation test because of its size and track, the quality of data-assimilated wind fields available to force models, and the wealth of measured waves and water levels. A total of 39 wind wave time histories, 362 water level time histories, and $82 \mathrm{HWMs}$ are available to describe the event. In the sections that follow, we describe the models and characterize the system, discuss how the storm evolved and impacted the region, and perform a detailed validation of these coupled wave and surge model hindcasts using the measured time series of waves and water levels as well as HWMs.

\section{SL16 model development}

\section{a. Hurricane wind field}

Hurricane wind fields for Gustav were developed using NOAA's Hurricane Research Division Wind Analysis System $\left(\mathrm{H}^{*}\right.$ Wind $)$ to assimilate winds in the core from extensive aircraft, buoy, space-based remote sensing, wind tower, and other measurement data (Powell et al. 1996, 1998, 2010). $\mathrm{H}^{*}$ Wind analyses of Gustav benefited from the deployment of stepped-frequency microwave radiometers aboard the Air Force Hurricane Hunter Aircraft (Uhlhorn et al. 2007), increasing the availability of high radial resolution surface winds since the Katrina wind field postanalysis (Ebersole et al. 2007). Additional improvements to the $\mathrm{H}^{*}$ Wind analysis included the use of improved terrain conversions (Vickery et al. 2009) and high-resolution tower data from Texas Tech University and the Florida Coastal Monitoring Program. $\mathrm{H}^{*}$ Wind analyses cover an $8^{\circ}$ latitude-longitude domain on a 3-h frequency for Gustav's entire Gulf track. To provide forcing to our wave and circulation models, the $\mathrm{H}^{*}$ Wind fields are blended with larger-scale winds using the Interactive Objective Kinematic Analysis (IOKA) system (Cox et al. 1995; Cardone and Cox 2007). The resulting wind fields apply to the reference condition of 10-m height, 30-min "sustained" wind speed, and marine exposure. Wind fields were interpolated to 15 -min intervals, starting at 0000 UTC 


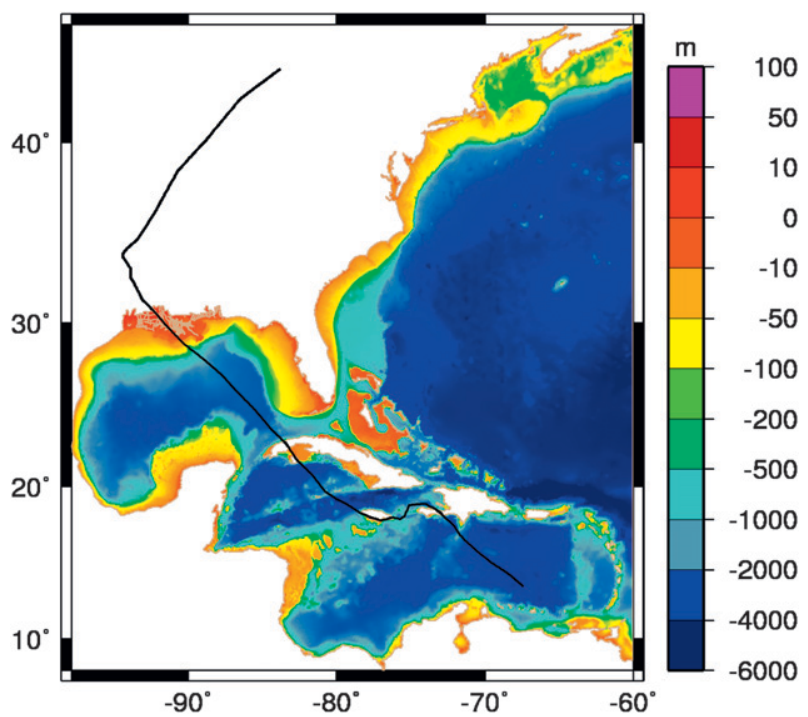

FIG. 4. Bathymetry (m) of the SL16 mesh. Gustav's track is shown with a solid black line.

26 August 2008 (approximately 6.5 days before landfall) and ending at 0000 UTC 4 September 2008 (approximately 2.5 days after landfall). The Gustav wind fields offer Gulfwide resolution on a $0.05^{\circ}$ mesh, with increased resolution of $0.015^{\circ}$ on a smaller mesh near landfall.

These resulting wind fields and Holland (1980) modelgenerated pressure fields are read and interpolated by ADCIRC onto its unstructured mesh and then passed to the wave models. ADCIRC applies a factor of 1.09 to convert from 30-min-averaged to 10-min-averaged wind speeds, and directional wind reduction factors are applied (Bunya et al. 2010). In addition, ADCIRC applies a wind drag coefficient based on recent analyses of the azimuthal dependence of the drag coefficient determined from mean GPS sonde wind speed profiles (Powell et al. 2003; Powell 2006). Data were inconclusive to determine whether an azimuthal drag dependence exists for nearcoastal areas. However, for the results based primarily on open-ocean, deepwater wind profiles, the drag coefficient increases in sectors where the winds are blowing across or counter in direction to the waves. ADCIRC detects the location and direction of the eye, and then the sector-based wind drag coefficients are applied as shown in Fig. 3. These wind drag coefficients are shared with SWAN.

WAM utilizes an atmospheric input source term based on Janssen (1991) that includes the net impact surface roughness resulting from a growing wave field, with an upper limit where the dependency of frictional velocity becomes linear with the equivalent neutral stable marine exposure wind field at $10 \mathrm{~m}$. STWAVE applies a drag coefficient consistent with Cardone (1969).

\section{b. Wave and surge models}

The coupling of ADCIRC and STWAVE is performed through external files. WAM is run first, on a Gulf-wide mesh with fixed $0.05^{\circ}$ resolution, to generate boundary conditions at the nearshore, structured

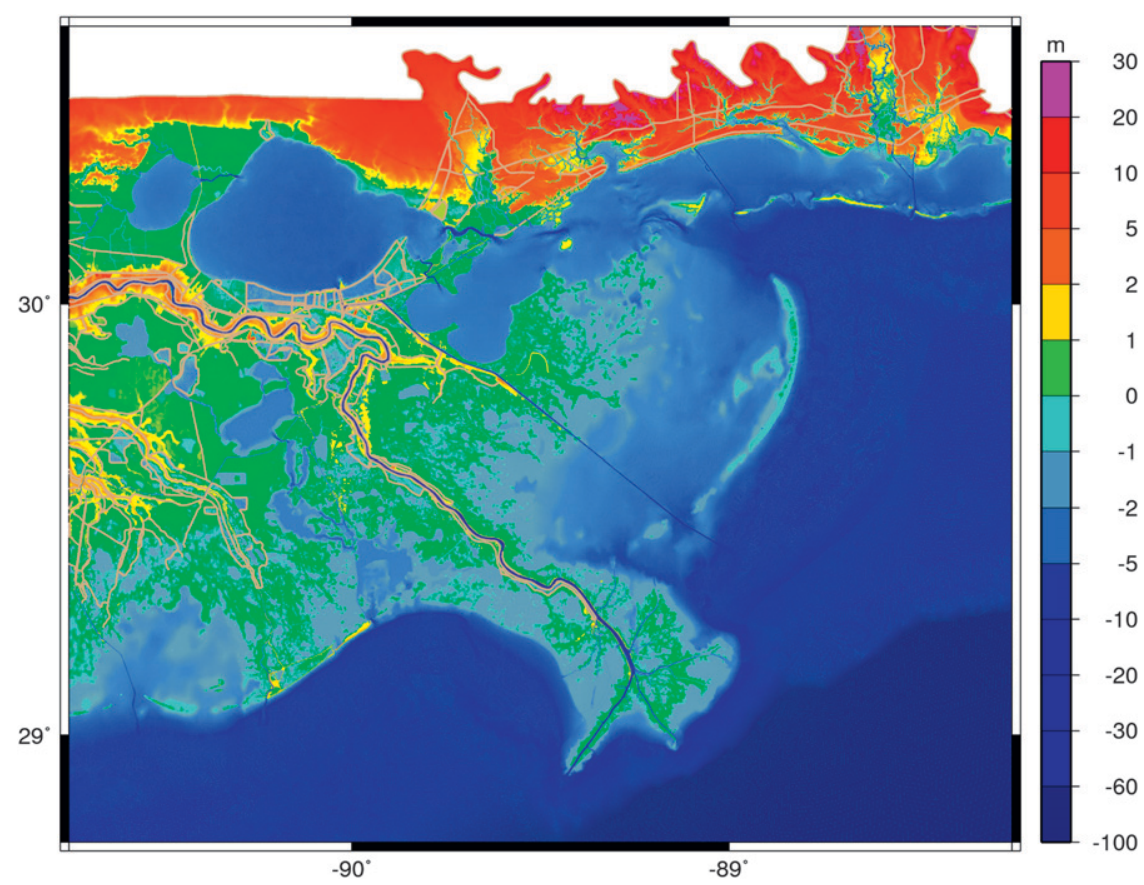

FIG. 5. Bathymetry/topography (m) of the SL16 mesh in southeastern Louisiana. 


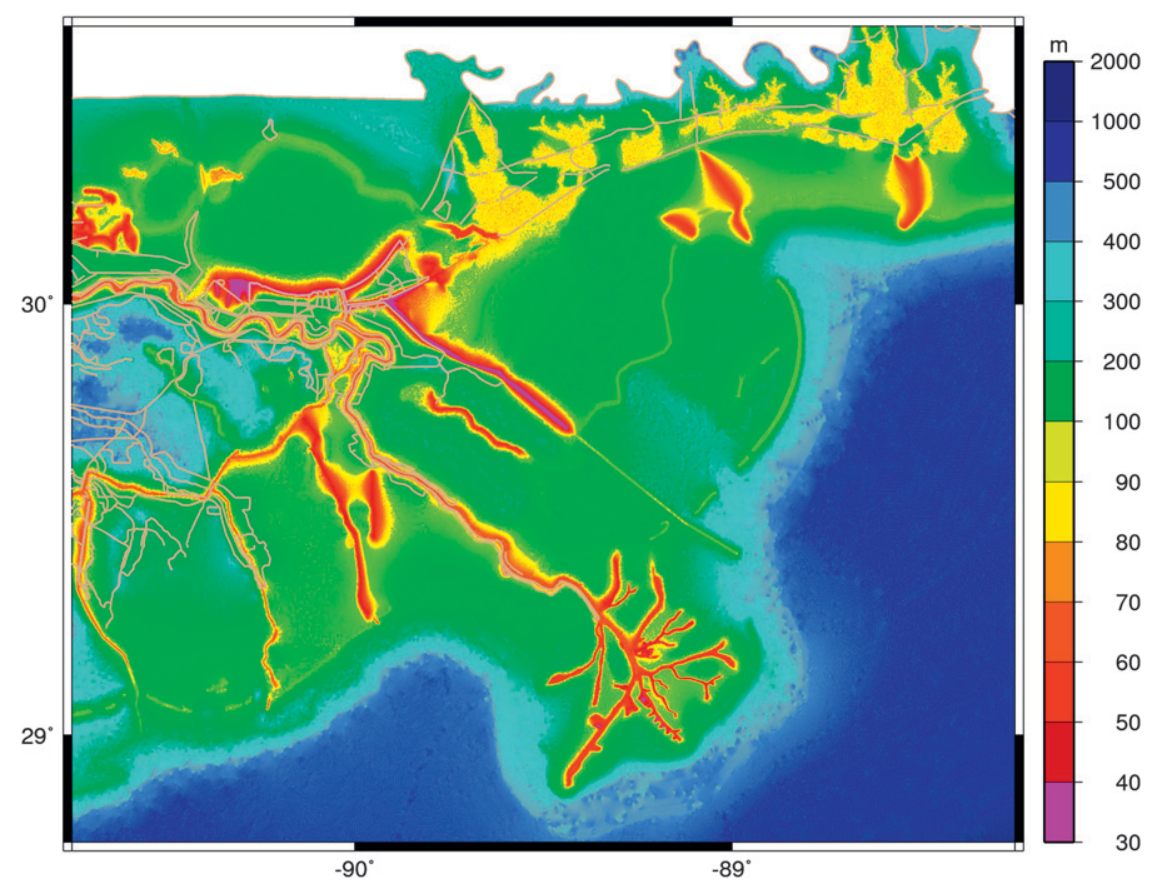

FIG. 6. Mesh resolution (m) of the SL16 mesh in southeastern Louisiana.

STWAVE meshes (Komen et al. 1994; Smith 2000; Smith et al. 2001; Günther 2005; Smith 2007). WAM is a thirdgeneration, discrete spectral wave model solving the action balance equation (including refraction and shoaling) and accounting for arbitrary water depth in source/sink term specification to compute the generation and dissipation of wave action. It uses 28 frequency bins that increase in bandwidth logarithmically, and 24 directional bins of constant width $15^{\circ}$. ADCIRC is then run, and its wind fields and water levels are output to use as forcing for a set of STWAVE simulations on two nearshore meshes with 200-m resolution. STWAVE solves the action balance equation along piecewise, backward-traced wave rays. STWAVE utilizes 45 frequency bins, in the range of $0.0314-2.08 \mathrm{~Hz}$ and increasing in bandwidth logarithmically $(\Delta \sigma / \sigma \approx 0.1)$, and 72 directional bins of constant width $5^{\circ}$. This coupling provides good matches for nearshore waves and storm surge and a realistic wave setup (Bunya et al. 2010; Dietrich et al. 2010).

In the coupling of SWAN and ADCIRC, the unstructured-mesh version of SWAN is applied so that both models run on the same mesh, thus eliminating the need for interpolation between models (Zijlema 2010; Dietrich et al. 2011). Water levels and currents are computed by ADCIRC and passed at each SWAN time step. SWAN solves the action balance equation for the wave action (Booij et al. 1999; Ris et al. 1999). The SWAN time step and coupling interval are $600 \mathrm{~s}$ (Dietrich et al. 2011). The wave directions are discretized into 36 directional bins of constant width $10^{\circ}$, and the frequencies are discretized over 40 bins on a logarithmic scale, over the range $0.031-1.42 \mathrm{~Hz}$. The hindcast uses the wind input formulation based on Snyder et al. (1981), the modified whitecapping expression of Rogers et al. (2003), and quadruplet nonlinear interactions via the discrete interaction approximation (Hasselmann et al. 1985). For the shallow-water source terms, depth-induced breaking is computed with a spectral version of the model of Battjes and Janssen (1978) with the breaking index $\gamma=0.73$; bottom friction is described below. Wave refraction is enabled in regions where the resolution of the bathymetry is sufficient to prevent spurious wave refraction over one spatial element, specifically in the northern Gulf.

ADCIRC solves the 2D and 3D shallow-water equations for water levels $\zeta$ and the vertically integrated momentum equations for currents $U$ and $V$ (Kolar et al. 1994; Luettich and Westerink 2004; Dawson et al. 2006). The depth-averaged 2D equations are employed herein because there is significant, wave-induced vertical mixing on the continental shelf. The unstructured mesh allows for resolution to increase as waves and surge propagate from the deeper Gulf to the continental shelf and into the inlets and floodplains of coastal regions. ADCIRC uses a 1-s time step in the present hindcast.

\section{c. SL16 unstructured mesh}

This study employs the high-resolution SL16 mesh, which has 5035113 vertices and 9945623 triangular 


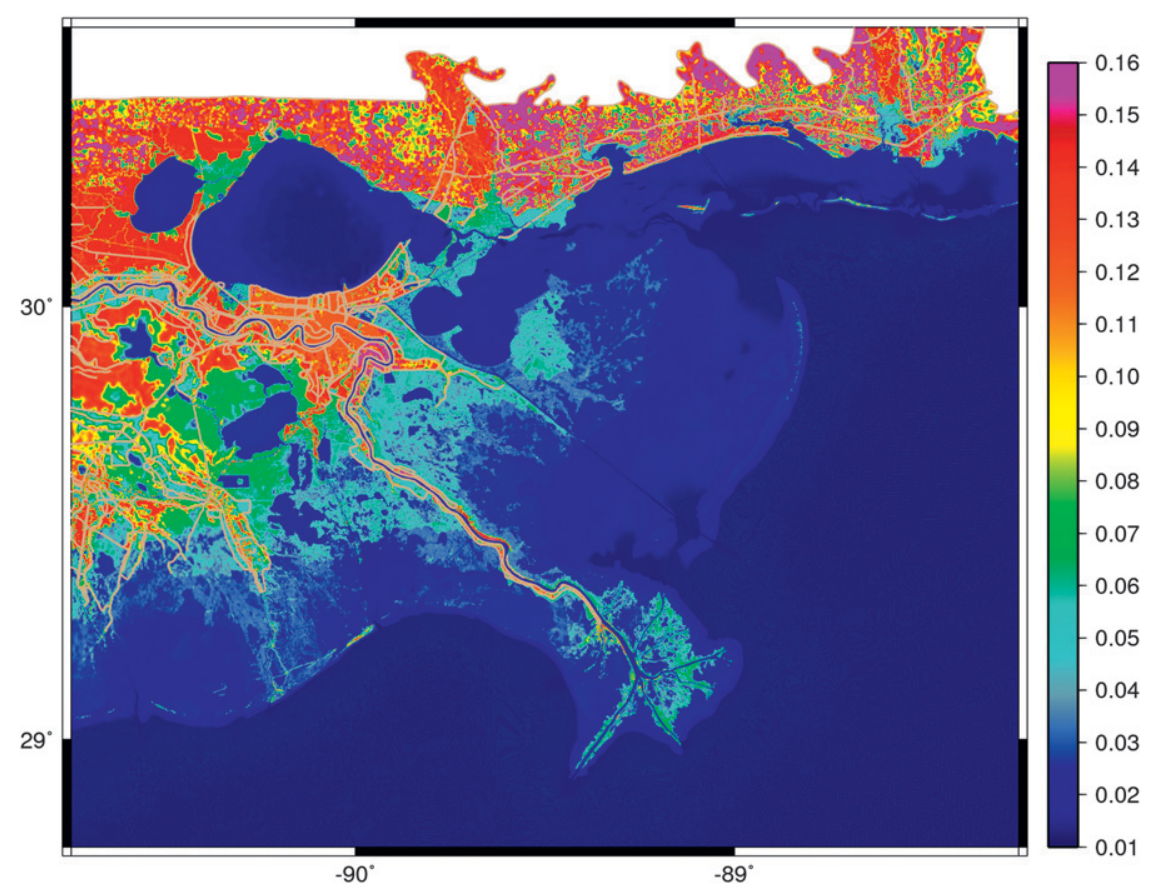

FIG. 7. Manning's $n$ values for the SL16 mesh in southeastern Louisiana.

elements. As shown in Figs. 4 and 5, the mesh provides coverage of southern Louisiana, Mississippi, and Alabama, and it extends outward through the Gulf of Mexico and the Caribbean Sea to the western North Atlantic Ocean. This wide coverage allows tides to be specified at a boundary outside the resonant basin of the Gulf, and storms to be started inside the domain but far from the area of interest. The mesh resolution varies from 15 to $20 \mathrm{~km}$ in the Atlantic Ocean to $4-6 \mathrm{~km}$ in the Gulf, $1 \mathrm{~km}$ on the continental shelf, and, as highlighted in Fig. 6, 100-200 $\mathrm{m}$ in the wave-breaking zones and marshes of southern Louisiana and down to $20-50 \mathrm{~m}$ in small-scale channels.

Bathymetry in the Gulf was specified using the 1-arcminute global relief model (ETOPO1) in deep water (Amante and Eakins 2009) and coastal relief digital elevation models (DEMs) nearshore (NOAA 2008). Bathymetry in nearshore water bodies and channels, such as the Mississippi River, Lakes Borgne and Pontchartrain, and the Rigolets and Chef Menteur passes, was applied from recent surveys by the USACE and NOAA. Topography in the marshes was specified based on the land cover databases described below, while topography farther inland was specified using lidar data (see online http://atlas. lsu.edu/lidar/). These bathymetric/topographic data were applied via mesh-scale averaging to avoid irregularities or discontinuities in the SL16 mesh. Levee and road systems that are barriers to flood propagation are included, with geographical placement based on USACE surveys and heights from USACE or lidar; these levees are handled as lines of vertices or submesh-scale weirs (Westerink et al. 2008). Levee and road heights were established to reflect pre-Gustav conditions.

\section{d. Adjustments for steric expansion and vertical datum}

Water levels are increased at the beginning of the ADCIRC simulation to account for the vertical datum and the intra-annual mean sea surface variability of the Gulf of Mexico. The computed water levels in ADCIRC are relative to local mean sea level, and they are adjusted to the North American Vertical Datum of 1988 updated to the 2004.65 epoch, NAVD88 (2004.65), by adding $0.134 \mathrm{~m}$ (Garster et al. 2007; Bunya et al. 2010). A further adjustment is required because of the intraannual fluctuation in sea level due to the thermal expansion of the Gulf and other processes. Long-term NOAA stations at Dauphin Island, Mississippi, and Grand Isle and Eugene Island, Louisiana, indicate a steric increase of $0.086 \mathrm{~m}$ in the averaged water levels in early September (http://tidesandcurrents.noaa.gov/sltrends/sltrends.html). Thus, the combined increase in water levels for Gustav is $0.134 \mathrm{~m}+0.086 \mathrm{~m}=0.22 \mathrm{~m}$.

\section{e. Integrally coupled bottom friction}

Hydraulic friction is computed in ADCIRC using a Manning's $n$ formulation (Fig. 7), with spatially variable values that are applied based on land-cover databases (Bunya et al. 2010), specifically data from the 
TABLE 1. Geographic location by type and number shown in Fig. 1.

\begin{tabular}{|c|c|}
\hline \multicolumn{2}{|c|}{ Rivers and channels } \\
\hline 1 & Rigolets \\
\hline 2 & Chef Menteur Pass \\
\hline 3 & Gulf Intracoastal Waterway (GIWW) \\
\hline 4 & Mississippi River Gulf Outlet (MRGO) \\
\hline 5 & Inner Harbor Navigational Canal (IHNC) \\
\hline 6 & Mississippi River \\
\hline \multicolumn{2}{|c|}{ Bays, lakes, and sounds } \\
\hline 7 & Chandeleur Sound \\
\hline 8 & Breton Sound \\
\hline 9 & Lake Borgne \\
\hline 10 & Lake Pontchartrain \\
\hline 11 & Lake Cataouatche \\
\hline 12 & Lake Salvador \\
\hline 13 & Little Lake \\
\hline 14 & Barataria Bay \\
\hline 15 & Terrebonne Bay \\
\hline \multicolumn{2}{|l|}{ Islands } \\
\hline 16 & Dauphin Island \\
\hline 17 & Mississippi Sound Islands \\
\hline 18 & Chandeleur Islands \\
\hline 19 & Grand Isle \\
\hline \multicolumn{2}{|l|}{ Places } \\
\hline 20 & Louisiana-Mississippi Shelf \\
\hline 21 & Biloxi marsh \\
\hline 22 & Caernarvon marsh \\
\hline 23 & "Bird's foot" of the Mississippi River Delt \\
\hline 24 & Plaquemines Parish \\
\hline 25 & English Turn \\
\hline 26 & Braithwaite \\
\hline 27 & New Orleans \\
\hline 28 & Port Fourchon \\
\hline
\end{tabular}

Louisiana Gap Analysis Program (LA-GAP; http://atlas. lsu.edu/rasterdown.htm), the Mississippi Gap Analysis Program (MS-GAP; http://www.basic.ncsu.edu/segap/ index.html), and the Coastal Change Analysis Program (C-CAP; http://www.csc.noaa.gov/digitalcoast/ data/ccapregional/). These values are summarized in Tables 2-4 On the continental shelf in the Gulf of Mexico, the values have been set to $n=0.022$ for sand/ gravel bottoms and $n=0.012$ for muddy bottoms, such as the Louisiana-Mississippi continental shelf (Buczkowski et al. 2006). These values also enable the currents and geostrophic setup associated with the forerunner surge in Hurricane Ike (Kennedy et al. 2011).

STWAVE applies bottom friction based on the same Manning's $n$ values used by ADCIRC (Smith 2007), but with a minimum of $n \geq 0.03$. In addition, the integrated coupling of SWAN+ADCIRC allows for friction to be adjusted during the simulation, based on the computed solution of the model components. This hindcast utilizes the formulation of Madsen et al. (1988), who employ
TABLE 2. Manning's $n$ values for LA-GAP classification.

\begin{tabular}{clc}
\hline \hline LA-GAP Class & \multicolumn{1}{c}{ Description } & Manning's $n$ \\
\hline 1 & Fresh marsh & 0.070 \\
2 & Intermediate marsh & 0.065 \\
3 & Brackish marsh & 0.060 \\
4 & Saline marsh & 0.035 \\
5 & Wetland forest deciduous & 0.140 \\
6 & Wetland forest evergreen & 0.160 \\
7 & Wetland forest mixed & 0.150 \\
8 & Upland forest deciduous & 0.160 \\
9 & Upland forest evergreen & 0.180 \\
10 & Upland forest mixed & 0.170 \\
11 & Dense pine thicket & 0.180 \\
12 & Wetland scrub/shrub deciduous & 0.065 \\
13 & Wetland scrub/shrub evergreen & 0.080 \\
14 & Wetland scrub/shrub mixed & 0.070 \\
15 & Upland scrub/shrub deciduous & 0.075 \\
16 & Upland scrub/shrub evergreen & 0.090 \\
17 & Upland scrub/shrub mixed & 0.080 \\
18 & Agriculture/crops/grass & 0.050 \\
19 & Vegetated urban & 0.120 \\
20 & Nonvegetated urban & 0.120 \\
21 & Wetland barren & 0.030 \\
22 & Upland barren & 0.035 \\
23 & Water & 0.025 \\
\hline
\end{tabular}

a roughness length $z_{o}$, which is expressed in terms of the water depth $H$ and the Manning's $n$ :

$$
z_{o}=H \exp \left[-\left(1+\frac{\kappa H^{1 / 6}}{n \sqrt{g}}\right)\right],
$$

where $\kappa=0.4$ is the von Kármán constant and $g$ is the gravitational acceleration (Bretschneider et al. 1986). New roughness lengths are computed at each SWAN time step, based on the computed ADCIRC water depth and Manning's $n$ value at each mesh vertex. The Manning's $n$ values are raised to $n \geq 0.03$ to prevent the use of unrealistically small roughness lengths in SWAN; the values remain unchanged for ADCIRC.

\section{f. Riverine inflows}

River inflows are specified for the Mississippi and Atchafalaya Rivers at Baton Rouge and Simmesport, Louisiana, respectively, using a river-wave radiation boundary condition (Westerink et al. 2008; Bunya et al. 2010). A steady flow boundary condition is applied during a 0.5 -day hyperbolic ramp, and then the river is allowed to reach equilibrium over the next 3.5 days. After four days of simulation, the boundary condition is switched to a wave radiation boundary condition, and tide, wind, pressure, and wind wave forcings are applied throughout the system. River flow rates were determined from the New Orleans District of the U.S. Army Corps of 
TABLE 3. Manning's $n$ values for MS-GAP classification.

\begin{tabular}{|c|c|c|}
\hline MS-GAP Class & Description & Manning's $n$ \\
\hline 1 & Agriculture & 0.050 \\
\hline 2 & Freshwater & 0.025 \\
\hline 3 & Aquaculture & 0.045 \\
\hline 4 & Estuarine water & 0.025 \\
\hline 6 & Farmed wetlands & 0.035 \\
\hline 7 & Estuarine emergent & 0.050 \\
\hline 8 & Estuarine woody & 0.140 \\
\hline 9 & Palustrine emergent & 0.060 \\
\hline 10 & Bottomland hardwood & 0.140 \\
\hline 11 & Riverine swamp & 0.140 \\
\hline 12 & Pine savannah & 0.090 \\
\hline 13 & Freshwater shrub/scrub & 0.075 \\
\hline 14 & Palustrine nonvegetated & 0.035 \\
\hline 15 & Transportation & 0.032 \\
\hline 16 & High-density urban & 0.150 \\
\hline 24 & Urban freshwater & 0.025 \\
\hline 25 & Wet soil/water/shadow & 0.040 \\
\hline 26 & Urban pine & 0.180 \\
\hline 27 & Urban hardwood & 0.160 \\
\hline 28 & Urban low herbaceous & 0.070 \\
\hline 29 & Urban grassy/pasture & 0.055 \\
\hline 30 & Bare urban I & 0.120 \\
\hline 31 & Bare urban II & 0.120 \\
\hline 32 & Clear cuts & 0.036 \\
\hline 50 & Low-density pine & 0.160 \\
\hline 51 & Medium-density pine & 0.180 \\
\hline 52 & High-density pine & 0.200 \\
\hline 53 & Medium-density hardwood & 0.170 \\
\hline 54 & High-density hardwood & 0.170 \\
\hline 55 & Mixed forest & 0.160 \\
\hline 56 & Recent harvest & 0.045 \\
\hline 57 & Cypress/tupelo & 0.180 \\
\hline 60 & Agriculture & 0.050 \\
\hline 61 & Grassy/pasture/range & 0.050 \\
\hline 62 & Low herbaceous vegetation & 0.050 \\
\hline 63 & Evergreen shrub & 0.080 \\
\hline 71 & Wetland & 0.050 \\
\hline 80 & Bare & 0.035 \\
\hline 81 & Sand bar/beach & 0.030 \\
\hline
\end{tabular}

Engineers (http://www.mvn.usace.army.mil) and were applied as average values during the seven days surrounding landfall. The flow rates were 8920 and $3823 \mathrm{~m}^{3} \mathrm{~s}^{-1}$ for the Mississippi and Atchafalaya Rivers, respectively.

\section{Measured time series and high-water marks}

Gustav is characterized by measurement data that describe how the storm evolved as it traversed the Gulf and made landfall in southeast Louisiana. More permanent gauges survived Gustav than Katrina, partly due to efforts to harden the gauges and increase their reliability. Additional gauges were deployed before landfall in regions such as the marshes and nearshore that have been underrepresented. The following sections describe the
TABLE 4. Manning's $n$ values for C-CAP classification.

\begin{tabular}{clc}
\hline \hline C-CAP Class & \multicolumn{1}{c}{ Description } & Manning's $n$ \\
\hline 2 & High-intensity developed & 0.120 \\
3 & Medium-intensity developed & 0.120 \\
4 & Low-intensity developed & 0.120 \\
5 & Developed open space & 0.035 \\
6 & Cultivated land & 0.100 \\
7 & Pasture/hay & 0.050 \\
8 & Grassland & 0.035 \\
9 & Deciduous forest & 0.160 \\
10 & Evergreen forest & 0.180 \\
11 & Mixed forest & 0.170 \\
12 & Scrub/shrub & 0.080 \\
13 & Palustrine forested wetland & 0.150 \\
14 & Palustrine scrub/shrub wetland & 0.075 \\
15 & Palustrine emergent wetland & 0.060 \\
16 & Estuarine forested wetland & 0.150 \\
17 & Estuarine scrub/shrub wetland & 0.070 \\
18 & Estuarine emergent wetland & 0.050 \\
19 & Unconsolidated shore & 0.030 \\
20 & Bare land & 0.030 \\
21 & Open water & 0.025 \\
22 & Palustrine aquatic bed & 0.035 \\
23 & Estuarine aquatic bed & 0.030 \\
\hline
\end{tabular}

measurement data, which offer valuable descriptions of the hurricane behavior in those regions, and which provide excellent validation data for WAM, STWAVE, SWAN, and ADCIRC.

\section{a. NDBC waves}

The NDBC operates discus buoys throughout the Gulf; they have diameters that range from $3 \mathrm{~m}$ nearshore to $10-12 \mathrm{~m}$ in the deeper Gulf. They measure heave acceleration or vertical displacement, which are processed both on the buoy and then onshore to derive spectral wave energies, which are integrated to derive wave properties such as significant height, peak and mean period, and mean direction (http://www.ndbc.noaa.gov/). These measured wave properties are compared to modeled results from WAM, STWAVE, and SWAN at 12 NDBC buoys within the Gulf.

\section{b. CSI waves and water levels}

The CSI at Louisiana State University operates stations along the continental shelf offshore of Louisiana. Each station utilizes a digiquartz pressure transducer and a Marsh-McBirney current meter at depths of 1-2 m below mean sea level, and these measurements are processed to derive water depths and directional wave spectra [Wave-Current-Surge Information System (WAVCIS); http://www.wavcis.lsu.edu/]. The measured significant wave heights, peak periods, and water levels are compared to modeled results from STWAVE, 

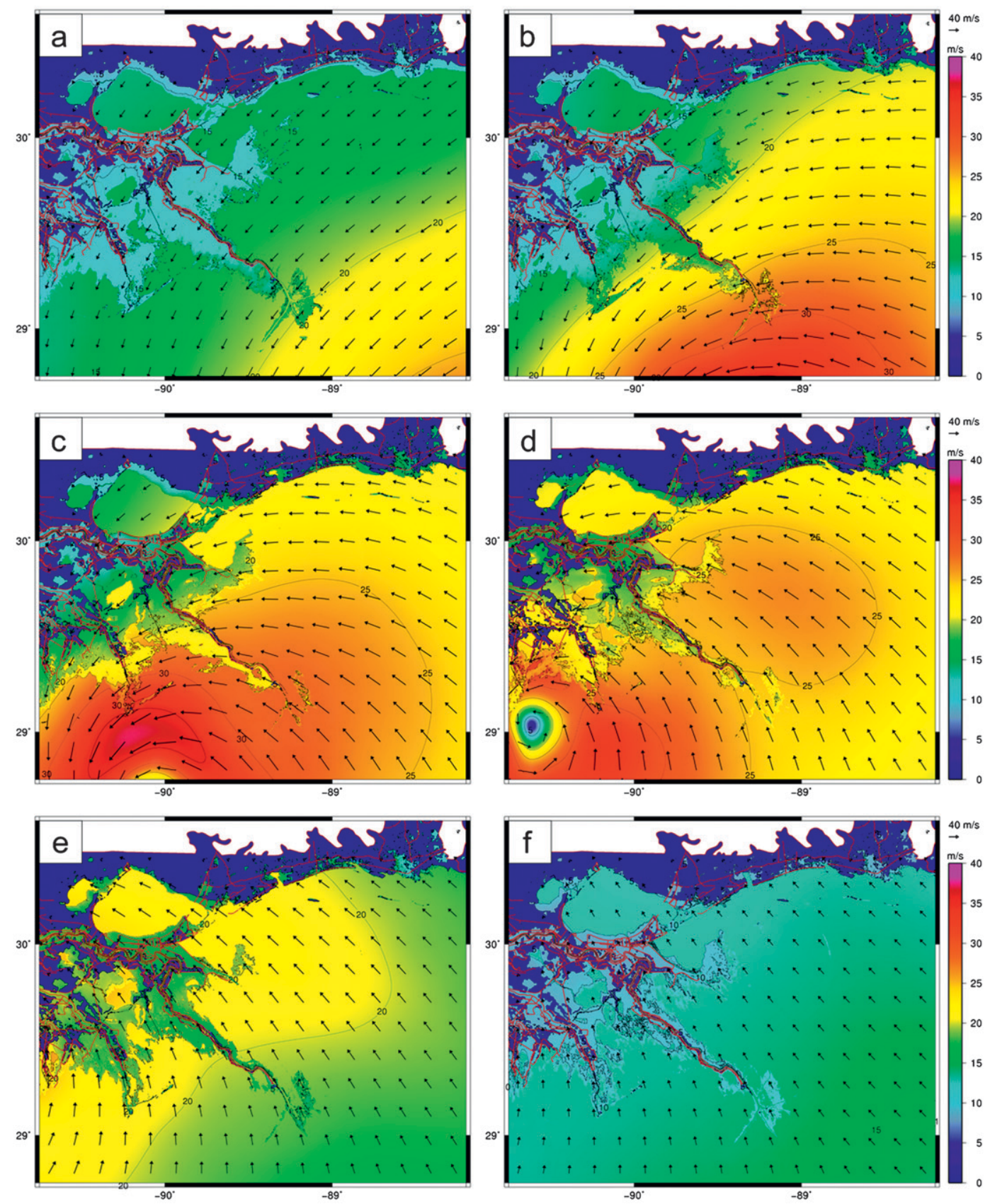

FIG. 8. Wind speeds $\left(\mathrm{m} \mathrm{s}^{-1}\right)$ in southeastern Louisiana during Hurricane Gustav at the following times: (a) 0200 UTC 1 Sep 2008 or approximately 12 h before landfall, (b) 0800 UTC 1 Sep 2008 or approximately 6 h before landfall, (c) 1100 UTC 1 Sep 2008 or approximately $3 \mathrm{~h}$ before landfall, (d) 1400 UTC 1 Sep 2008 or approximately landfall, (e) 1700 UTC 1 Sep 2008 or approximately $3 \mathrm{~h}$ after landfall, and (f) 0200 UTC 2 Sep 2008 or approximately $12 \mathrm{~h}$ after landfall.

SWAN, and ADCIRC at five stations located along the south-central Louisiana coast between the Vermilion and Barataria Bays. The water depths are converted to water levels by subtracting the mean depth at each station and accounting for the steric expansion and datum adjustment to NAVD88 (2004.65).

\section{c. AK waves and water levels}

The AK gauges measured waves and water levels using bottom-mounted pressure sensors recording continuously at $1 \mathrm{~Hz}$ (Kennedy et al. 2010). These gauges were deployed over two days prelandfall using helicopters, and 

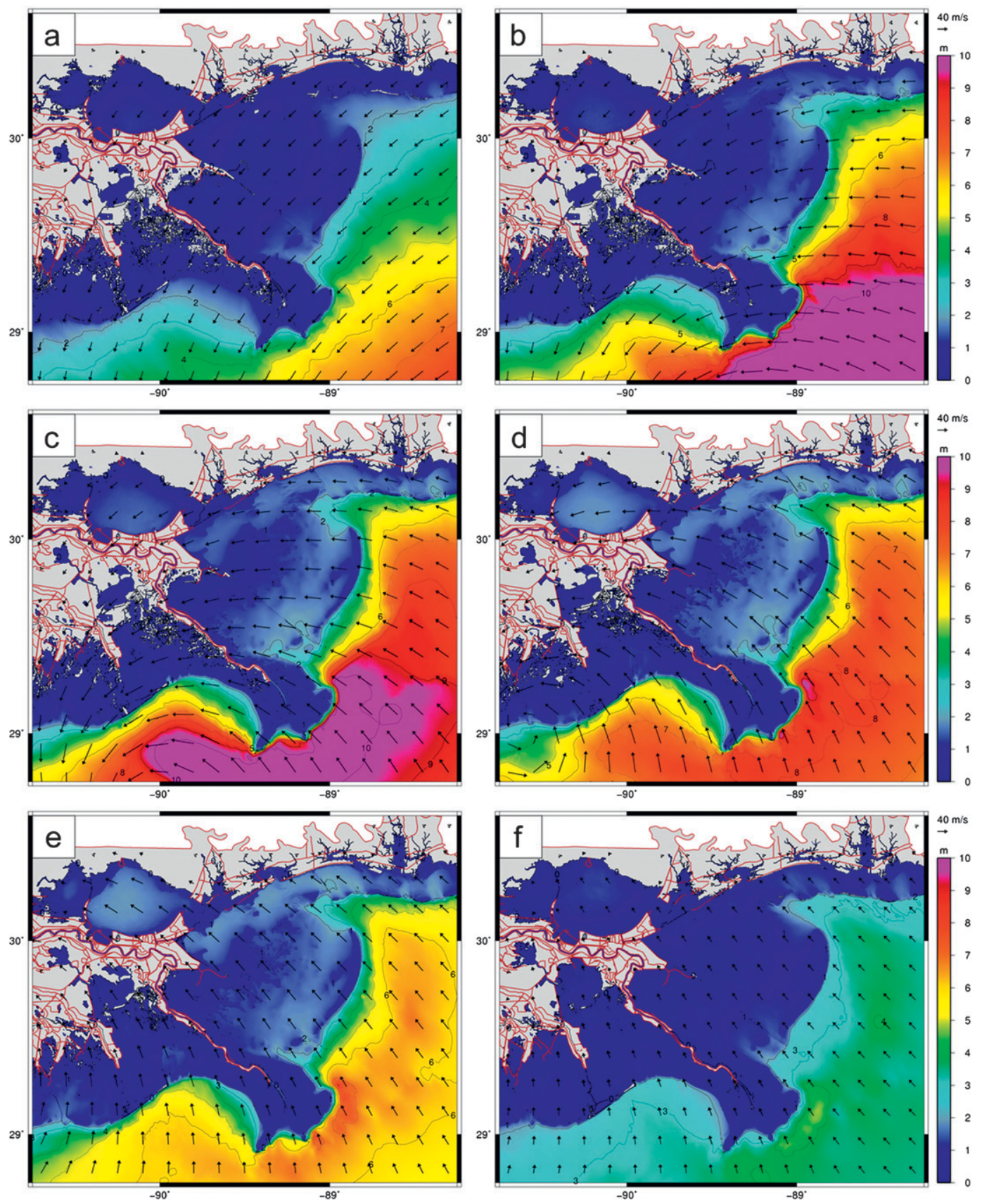

FIG. 9. Contours of SWAN significant wave heights $(\mathrm{m})$ and vectors of wind speeds $\left(\mathrm{m} \mathrm{s}^{-1}\right)$ in southeastern Louisiana during Hurricane Gustav. Times (a)-(f) are as in Fig. 8.

were retrieved using boats and divers poststorm. Measured absolute pressures were converted to water depths using records of atmospheric pressure. Surge elevations were then computed as the low-pass filtered water levels, while significant wave heights were computed using standard spectral methods, corrected using computed depth-averaged currents. The measured significant wave heights, peak periods, and water levels are compared to modeled results from STWAVE, SWAN, and ADCIRC at 16 gauges located along the coastline from Calcasieu Pass in the west to Pensacola Bay in the east.

\section{d. CHL waves and water levels}

CHL deployed three bottom-mounted pressure gauges in Biloxi marsh and three in Terrebonne marsh in depths 

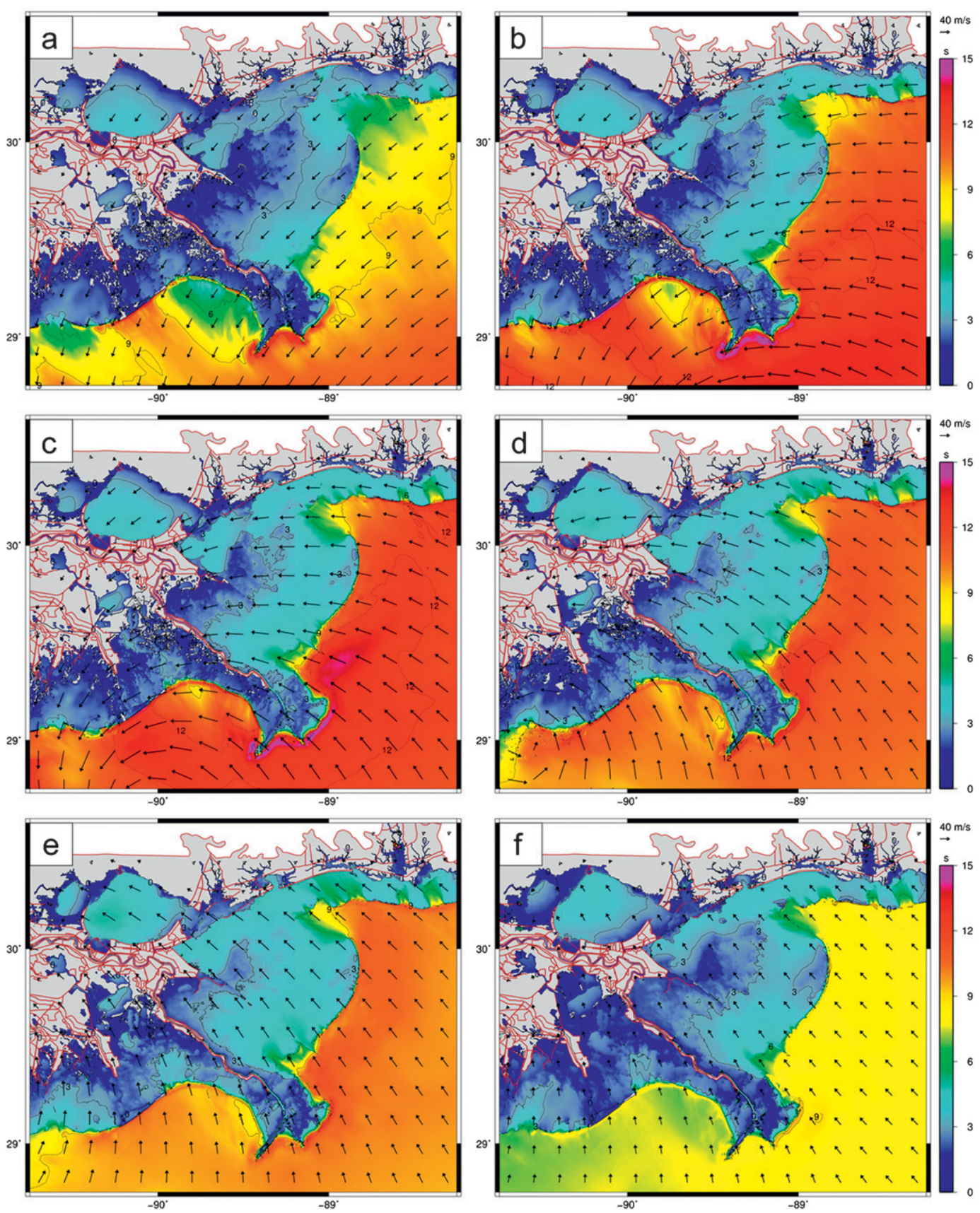

FIG. 10. Contours of SWAN mean wave periods (s) and vectors of wind speeds $\left(\mathrm{m} \mathrm{s}^{-1}\right)$ in southeastern Louisiana during Hurricane Gustav. Times (a)-(f) are as in Fig. 8.

of 0.5-1.2 m (Smith et al. 2011). The gauges were YSI $600 X \mathrm{XM}$ pressure gauges, and they were sampled hourly at $2 \mathrm{~Hz}$. Analysis of the inner marsh gauges resulted in peak periods around $2 \mathrm{~s}(0.5 \mathrm{~Hz})$ at the peak of the storm, which was near the high-frequency cutoff for the spectral analysis. This can result in amplification of noise and either over- or underestimation of wave height and underestimation of wave period.

\section{e. NOAA water levels}

NOAA operates tide measurement stations along the coastline of the United States (http://www.tidesandcurr ents.noaa.gov/). The measured water levels are compared to modeled results from ADCIRC at 23 stations along the coastline from Naples, Florida, to Vermilion Bay. The measured water levels are relative to NAVD88 (2004.65). 

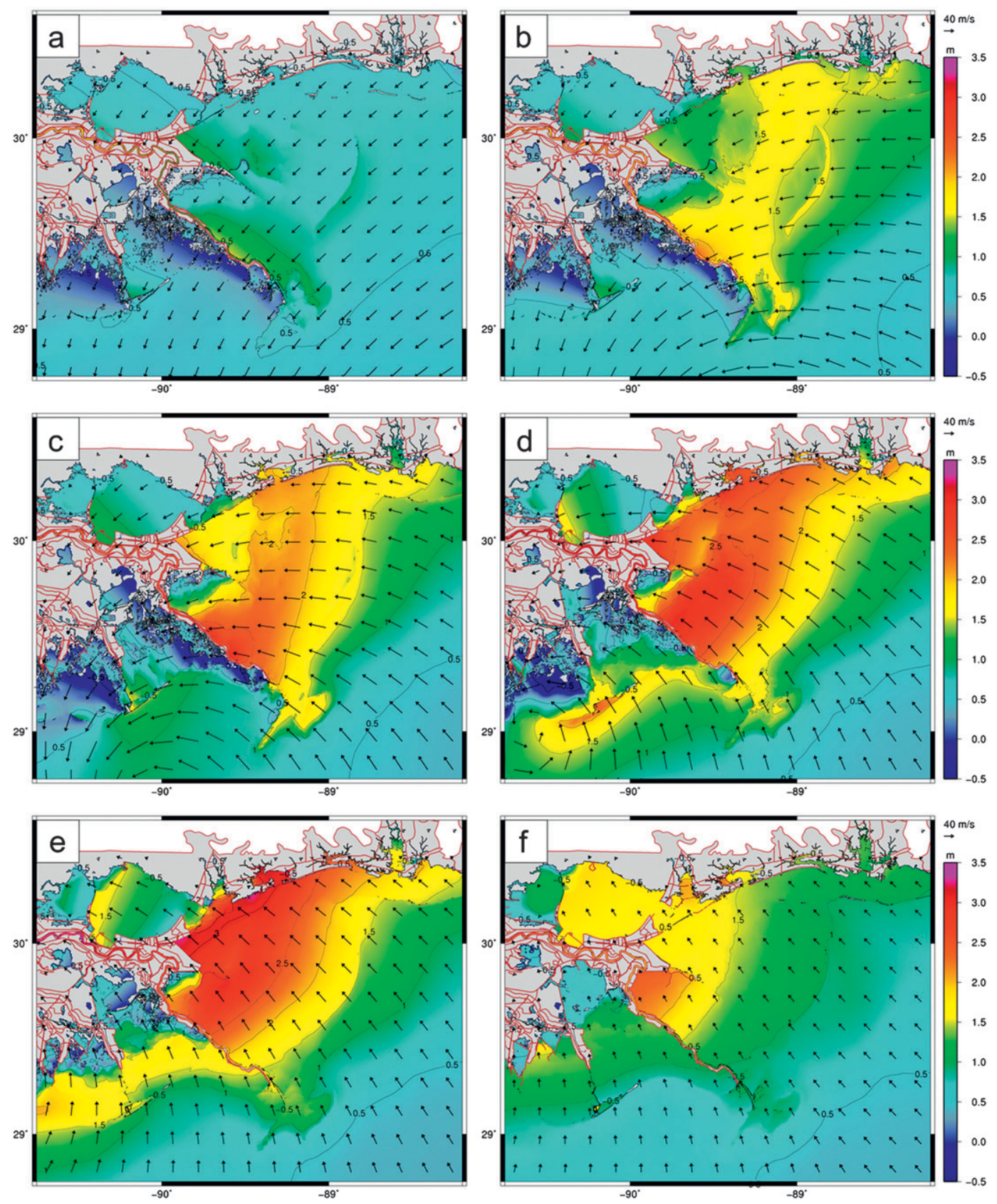

FIG. 11. Contours of ADCIRC water levels ( $\mathrm{m}$ relative to NAVD88 2004.65) and vectors of wind speeds ( $\mathrm{m} \mathrm{s}^{-1}$ ) in southeastern Louisiana during Hurricane Gustav. Times (a)-(f) are as in Fig. 8.

\section{f. USACE water levels}

The USACE operates pressure gauges throughout southern Louisiana, and a total of 42 gauges produced time series of water levels during part or all of Gustav. These data were obtained from the New Orleans District [USACE-Mississippi Valley Network (MVN)], and these water levels are relative to NAVD88 (2004.65).

\section{g. USGS water levels}

The USGS operates pressure gauges throughout southern Louisiana, and a total of 18 gauges produced time series of water levels during Gustav (D. J. Walters 2009, personal communication). Most of the gauges provide water levels relative to NAVD88 (2004.65), but a few gauges near the Terrebonne and Barataria Bays were reported relative to 


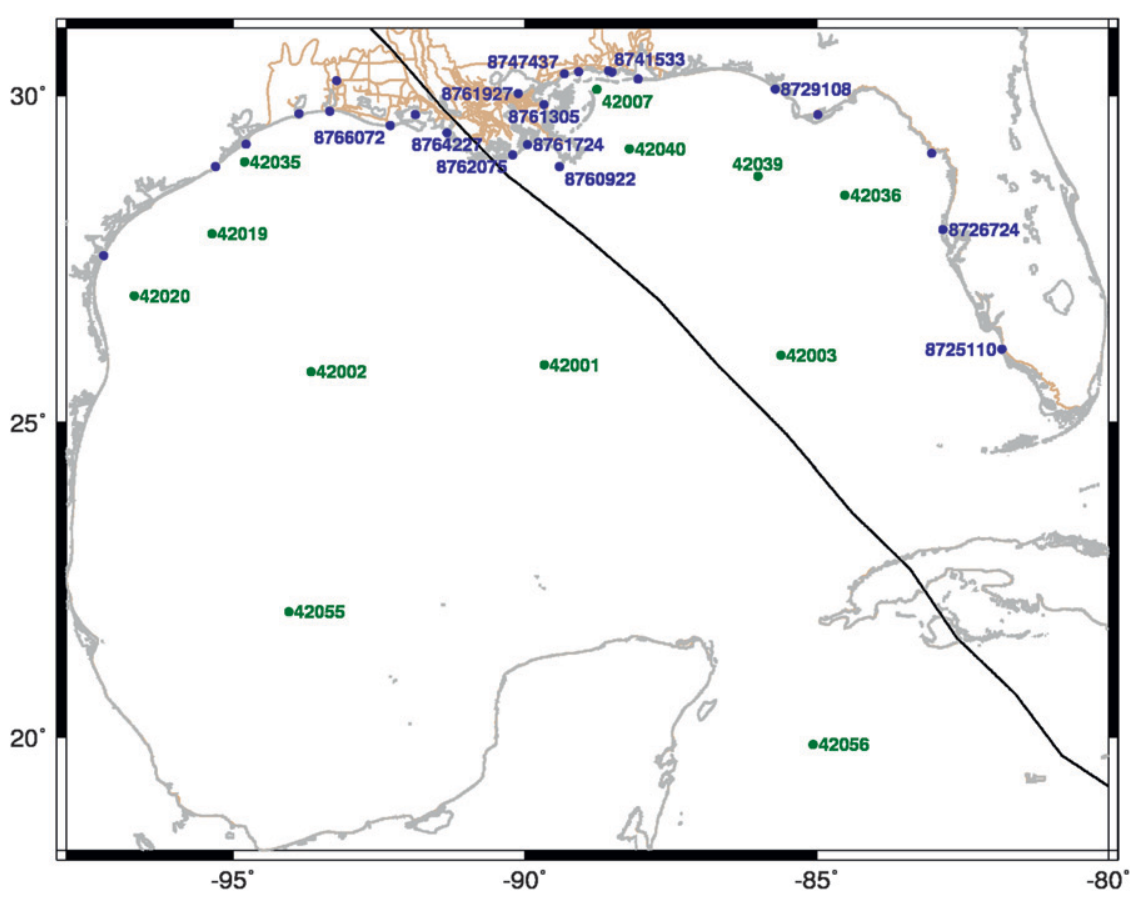

FIG. 12. Locations of wave NDBC buoys (green points) and NOAA water level stations (blue points) in the Gulf of Mexico. The Gustav track is shown in black, the coastline and water bodies are shown in gray, and the boundaries of the SL16 mesh are shown in brown. Unlabeled NOAA water level stations are included in the analysis in Table 6, but their time series plots are not shown in Fig. 21.

NGVD29. In addition, the USGS deployed 24 pressure gauges during Gustav that also produced time series of water levels during all or part of Gustav (D. J. Walters 2009, personal communication). These measured water levels are all relative to NAVD88 (2004.65).

\section{h. CRMS high-water marks}

The Coastwide Reference Monitoring System (http:// www.lacoast.gov/crms $2 /$ home.aspx) is a joint effort by federal and Louisiana state agencies to collect data about water quality. The gauges provide water levels relative to NAVD88 (2004.65). The dataset was trimmed to 232 gauges by removing gauges whose records were incomplete or otherwise were limited near the peak of the storm, and also the gauges with obvious datum inconsistencies. The peak hydrograph values at the 232 gauges are compared to modeled results from ADCIRC.

\section{i. FEMA high-water marks}

Finally, FEMA (2009b) measured HWMs relative to NAVD88 (2004.65) throughout southern Louisiana. These HWMs were collected in mid-November 2008, more than two months after Gustav made landfall, and thus they contain contributions from Hurricane Ike as well. The measured HWMs are compared to the modeled results from ADCIRC at 82 selected locations in southeast Louisiana. These marks were selected because they were indicated as being still-water measurements of excellent quality, and thus the effects of wave action should be minimized. In addition, they are located east of Gustav's track and judged to not contain contributions from Ike, by comparing to hydrographs from the sources listed above.

\section{Synoptic history and validation of Gustav}

The following sections describe the evolution of Gustav's winds (Fig. 8), waves (Figs. 9 and 10), and water levels (Fig. 11) in southeast Louisiana and the validation of the wave and surge models using data at reliable stations. Although station time series of wave parameters are shown from WAM, STWAVE, and SWAN, the water levels shown are produced via the coupling of SWAN+ ADCIRC. Geographical locations referenced in the text are summarized in Table 1 and shown in Fig. 1.

\section{a. Evolution of winds}

Gustav tracked through the Caribbean Sea (Fig. 4) and strengthened to a category 4 storm on the Saffir-Simpson scale, with maximum 10-min-averaged wind speeds of $69 \mathrm{~m} \mathrm{~s}^{-1}$ (Beven and Kimberlain 2009). After passing over western Cuba and into the Gulf, Gustav weakened 

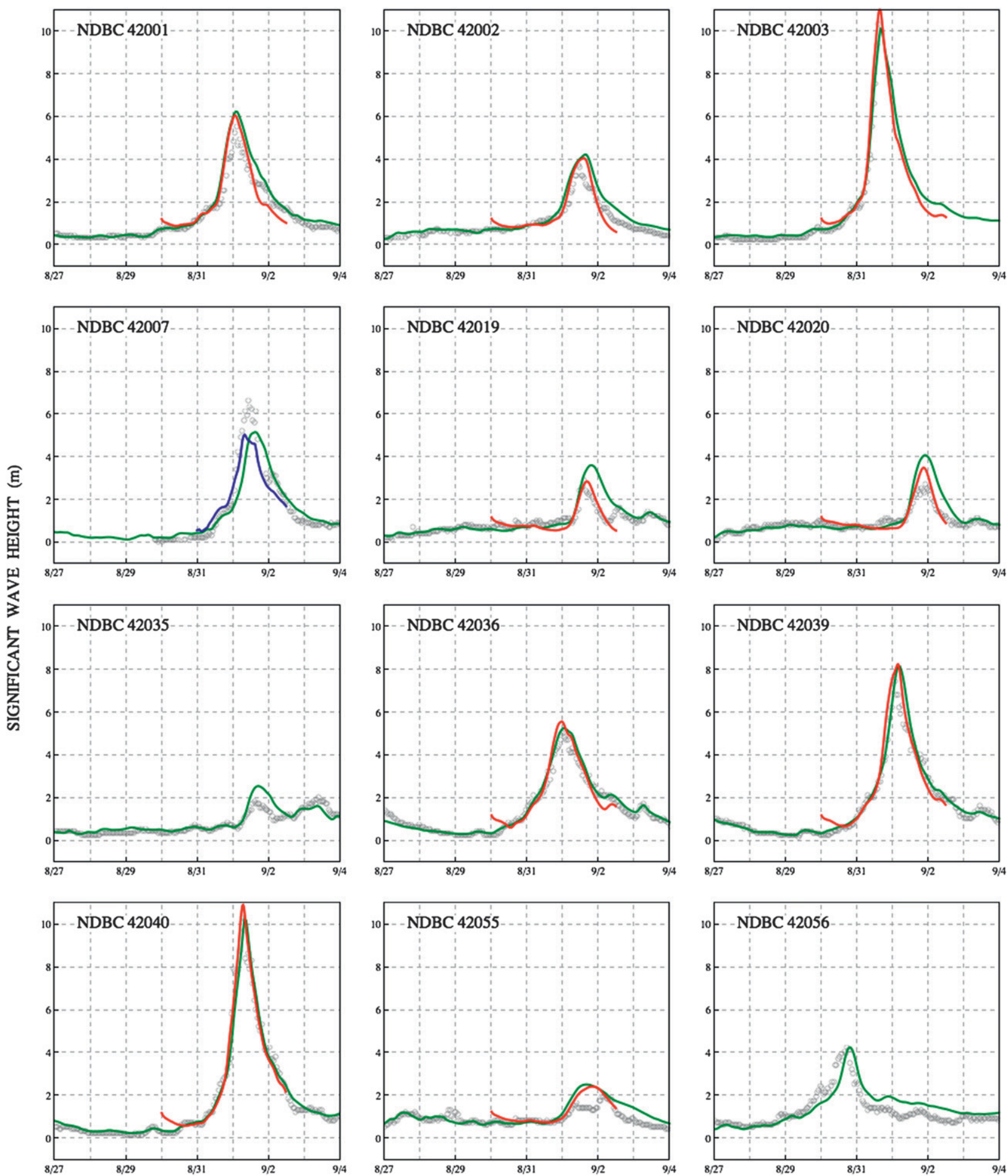

DATE IN 2008

FIG. 13. Time series of significant wave heights $(\mathrm{m})$ at the 12 NDBC buoys shown in Fig. 12. Measured NDBC values are shown with gray circles, while modeled results from SWAN (green), WAM (red), and STWAVE (blue) are shown with solid lines. Buoy 42003 stopped recording as the storm passed. 

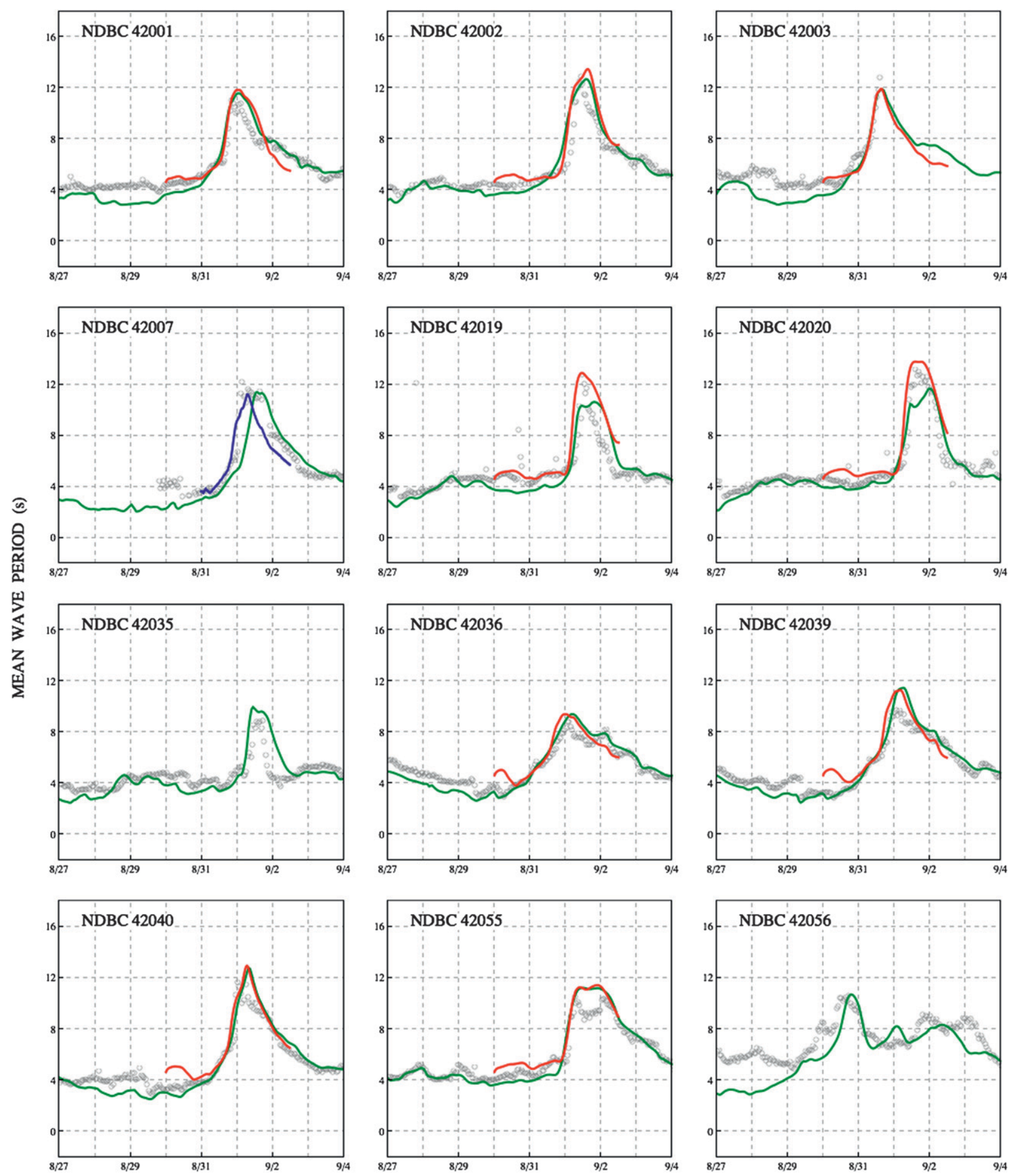

DATE IN 2008

FIG. 14. As in Fig. 13, but for mean periods (s). 

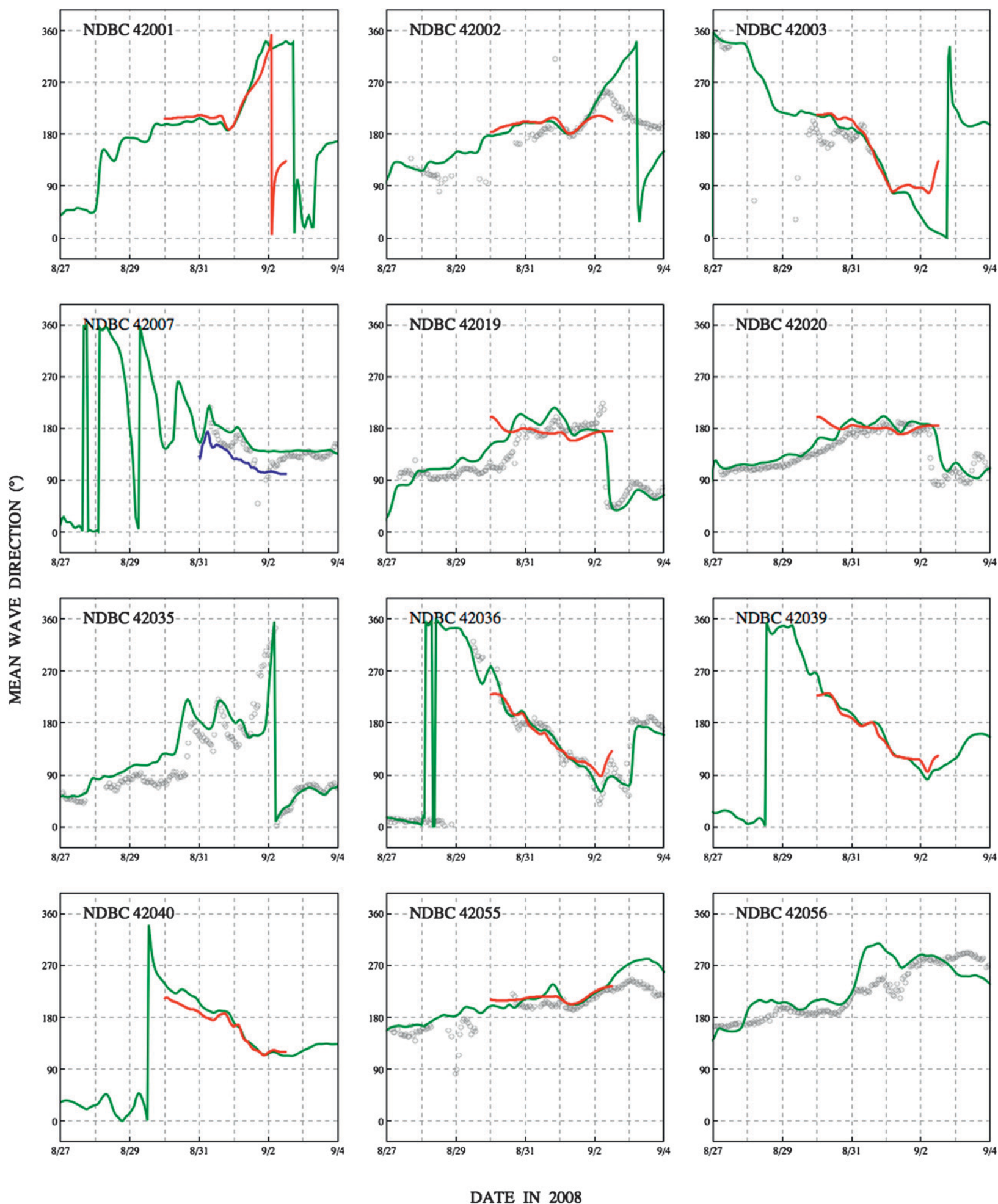

FIG. 15. As in Fig. 13, but for mean directions $\left({ }^{\circ}\right)$. 
TABLE 5. Summary of mean Scatter Index (SI) and mean normalized bias errors for the wave datasets. The mean errors for WAM and STWAVE are presented at all locations covered by their structured meshes. The mean errors for SWAN are presented at all locations, a subset of locations that are consistent with WAM/STWAVE, and a smaller subset without two NDBC buoys as indicated.

\begin{tabular}{|c|c|c|c|c|c|c|c|c|c|}
\hline \multirow[b]{2}{*}{ Dataset } & \multirow[b]{2}{*}{ Model } & \multirow[b]{2}{*}{ Locations } & \multirow{2}{*}{$\begin{array}{l}\text { No. of } \\
\text { locations }\end{array}$} & \multicolumn{2}{|c|}{$\begin{array}{c}\text { Significant wave } \\
\text { height }\end{array}$} & \multicolumn{2}{|c|}{$\begin{array}{c}\text { Peak wave } \\
\text { period }\end{array}$} & \multicolumn{2}{|c|}{$\begin{array}{l}\text { Mean wave } \\
\text { period }\end{array}$} \\
\hline & & & & SI & Bias & SI & Bias & SI & Bias \\
\hline \multirow[t]{6}{*}{ NDBC } & WAM & & 9 & 0.26 & 0.09 & 0.25 & 0.10 & 0.15 & 0.11 \\
\hline & STWAVE & & 1 & 0.28 & -0.07 & 0.26 & 0.02 & 0.16 & -0.05 \\
\hline & WAM/STWAVE & & 10 & 0.26 & 0.07 & 0.25 & 0.09 & 0.15 & 0.09 \\
\hline & SWAN & All & 12 & 0.32 & 0.15 & 0.29 & 0.04 & 0.17 & -0.02 \\
\hline & & Consistent & 10 & 0.31 & 0.14 & 0.26 & 0.03 & 0.16 & -0.02 \\
\hline & & Without 42019,42020 & 8 & 0.26 & 0.12 & 0.22 & -0.01 & 0.15 & -0.02 \\
\hline \multirow[t]{3}{*}{ CSI } & STWAVE & & 4 & 0.42 & 0.38 & 0.42 & 0.14 & 0.46 & 0.27 \\
\hline & SWAN & All & 5 & 0.34 & 0.22 & 0.46 & -0.07 & 0.35 & -0.05 \\
\hline & & Consistent & 4 & 0.35 & 0.20 & 0.41 & -0.05 & 0.37 & -0.04 \\
\hline \multirow[t]{3}{*}{ AK } & STWAVE & & 8 & 0.31 & 0.38 & 0.40 & 0.15 & - & - \\
\hline & SWAN & All & 16 & 0.31 & 0.28 & 0.45 & -0.02 & - & 一 \\
\hline & & Consistent & 8 & 0.33 & 0.24 & 0.39 & 0.03 & - & - \\
\hline \multirow[t]{2}{*}{ USACE-CHL } & STWAVE & & 6 & 0.61 & 0.56 & 1.63 & 0.49 & - & - \\
\hline & SWAN & & 6 & 0.51 & 1.08 & 1.28 & -0.19 & - & - \\
\hline \multirow[t]{6}{*}{ All } & WAM & & 9 & 0.26 & 0.09 & 0.25 & 0.10 & 0.15 & 0.11 \\
\hline & STWAVE & & 19 & 0.42 & 0.41 & 0.79 & 0.25 & 0.40 & 0.21 \\
\hline & WAM/STWAVE & & 28 & 0.37 & 0.31 & 0.61 & 0.20 & 0.32 & 0.14 \\
\hline & SWAN & All & 39 & 0.34 & 0.35 & 0.53 & -0.03 & 0.22 & -0.03 \\
\hline & & Consistent & 28 & 0.36 & 0.38 & 0.54 & -0.03 & 0.13 & -0.03 \\
\hline & & Without 42019,42020 & 26 & 0.35 & 0.39 & 0.54 & -0.05 & 0.22 & -0.03 \\
\hline
\end{tabular}

to category 3 and maintained this intensity until dropping to category 2 approximately $10 \mathrm{~h}$ before landfall. It progressed northwestward and made landfall as a category 2 storm in Terrebonne Bay in southern Louisiana. This behavior is in contrast to Katrina and Rita, which reached their peak intensities as category 5 storms while in the Gulf.

However, Gustav's outer extent of tropical-stormstrength winds was large enough to produce integrated kinetic energy values over $40 \mathrm{TJ}$, resulting in a rating of 3.0 (out of a possible 6.0) on the Surge Destructive Potential Scale at landfall (Powell and Reinhold, 2007). Tropicalstorm-strength winds reached the bird's foot of the Mississippi River delta approximately $12 \mathrm{~h}$ before landfall (Fig. 8a) and enveloped large portions of southern Louisiana and the Louisiana-Mississippi continental shelf by $6 \mathrm{~h}$ before landfall (Fig. 8b). Predominantly easterly coastal winds were relatively constant strength for $12-15 \mathrm{~h}$ as the storm moved through the region. On the shallow shelf, winds created local waves and surge, which were then pushed across the sounds and against the levee protection system. These winds also pushed surge into Lake Pontchartrain.

As Gustav neared landfall, its strongest winds were $30-35 \mathrm{~m} \mathrm{~s}^{-1}$, and they were limited to the narrow shelf to the southwest of the Mississippi River (Figs. 8c,d). Barataria and Terrebonne Bays experienced the worst of the hurricane winds as it made landfall. However, by this late stage, the winds shifted quickly to onshore and then continued onshore for several hours after landfall (Fig. 8e), aligning with the lake/marsh system connecting northward from Barataria Bay to the west bank of New Orleans.

Winds continued southeasterly over the LouisianaMississippi shelf for more than $12 \mathrm{~h}$ after landfall (Fig. 8f). Although the winds had weakened further, their direction over the shelf caused the winds to slow the recession of surge back into the deeper Gulf. The wind held the surge in Lake Pontchartrain, and it assisted the surge propagation over the Caernarvon marsh to the east of the river and over the marshes to the south and west of New Orleans.

\section{b. Evolution of waves}

Gustav generated waves with estimated significant heights of 12-15 $\mathrm{m}$ in deep water in the northeast quadrant of the storm, where the winds were strongest. These waves propagated as swell in all directions, but were largest to the east of the track. NDBC buoys 42036, 42039, and 42040 are located in the northeastern Gulf between Tampa Bay and the Mississippi River delta (Fig. 12), and their measured significant heights increased as the storm passed. At buoy 42040, the largest measured significant wave heights exceeded $10 \mathrm{~m}$ (Fig. 13). To the west of the track, wave heights decreased with distance from the track, with peak measured waves of $6 \mathrm{~m}$ at NDBC buoy 42001 decreasing to $3 \mathrm{~m}$ at buoys 42019 and 42020 nearer to Texas. As the storm passed, the mean wave periods also increased (Fig. 14), and the mean wave directions changed dramatically (Fig. 15). 


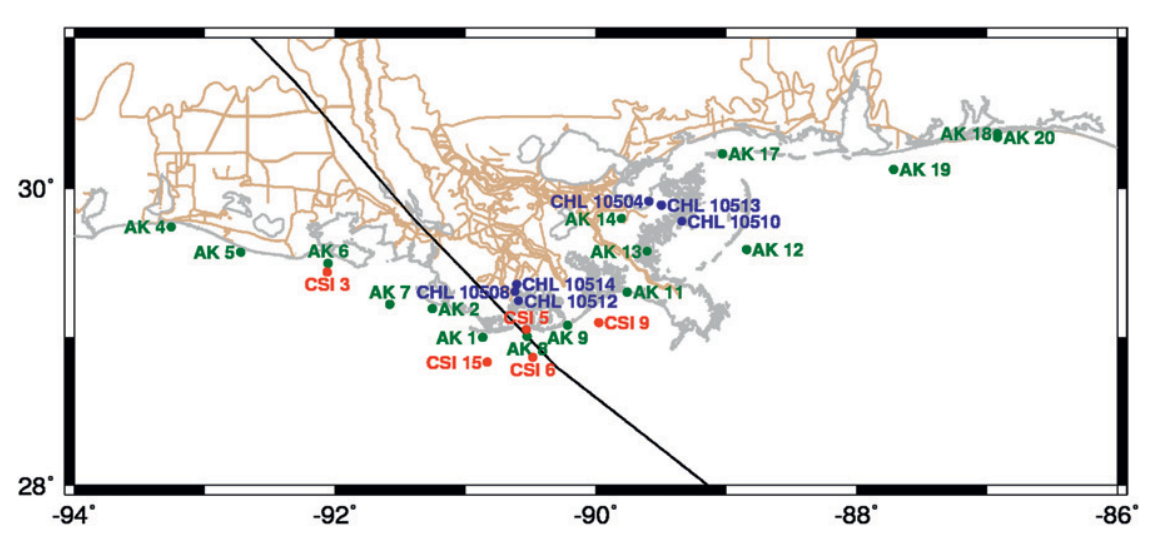

FIG. 16. Locations of the nearshore AK gauges (green points), CHL gauges (blue points), and CSI stations (red points) in the northern Gulf of Mexico. The Gustav track is shown in black, the coastline and water bodies are shown in gray, and the boundaries of the SL16 mesh are shown in brown.

In all of these validation plots, note the good agreement between the measured data and the computed results of WAM and SWAN. This agreement can be quantified through the use of the Scatter Index (SI)

$$
\mathrm{SI}=\frac{\sqrt{\frac{1}{N} \sum_{i=1}^{N}\left(E_{i}-\bar{E}\right)^{2}}}{\frac{1}{N} \sum_{i=1}^{N}\left|O_{i}\right|}
$$

and the normalized bias

$$
\operatorname{Bias}=\frac{\frac{1}{N} \sum_{i=1}^{N} E_{i}}{\frac{1}{N} \sum_{i=1}^{N}\left|O_{i}\right|},
$$

where $N$ is the number of observations, $E_{i}=S_{i}-O_{i}$ is the error between the modeled $S_{i}$ and measured $O_{i}$ values, and $\bar{E}$ is the mean error (Hanson et al. 2009). Thus the SI is the ratio of the standard deviation of the measured-to-modeled errors to the mean measured value. Table 5 summarizes the mean SI and mean normalized bias errors for all of the wave datasets, where the mean is computed as an average over the individual stations. At the NDBC buoys, the mean SI errors for the significant wave heights for WAM and STWAVE are in the range of 0.26 to 0.28 and the mean normalized biases are -0.07 to 0.09 , whereas the mean SI errors for SWAN are 0.31 to 0.32 and the mean normalized biases are 0.14 to 0.15 . The slightly larger SI errors for SWAN are due to two of the NDBC buoys on the Louisiana-Texas continental shelf (42019 and 42020); as shown in Fig. 13, the swell computed by SWAN at those buoys is too large. These buoys are farthest from Gustav's track in the Gulf and are located at the edge of the shelf break. We note that for other storms such as Katrina (2005), Rita (2005), and Ike (2008) with locally stronger and longer duration swell, these stations generally perform better with SWAN on the SL16 grid than for Gustav. Table 5 also includes the mean SI for the SWAN results at a subset of locations that are consistent with WAM/STWAVE, and a smaller subset without the NDBC buoys 42019 and 42020. When these buoys are removed from the analysis, the mean SI error for the significant wave heights for SWAN is 0.26 , which is comparable to the errors produced by WAM and STWAVE. The mean SI errors for the peak and mean wave periods are similar for the three wave models.

The waves generated near the track in deep water also propagated northward, where they moved onto the Louisiana-Mississippi continental shelf and dissipated because of changes in bathymetry and bottom friction. The largest and longest waves reached the Mississippi River delta 3-6 h before landfall (as computed in Figs. $9 \mathrm{~b}, \mathrm{c}$ and $10 \mathrm{~b}, \mathrm{c})$. These waves had significant heights of $10-12 \mathrm{~m}$ and mean periods of $12-15 \mathrm{~s}$, and they dissipated quickly because of the steep, narrow shelf near the delta. As the storm approached landfall, its local hurricane-strength winds created large waves offshore of the Barataria and Terrebonne Bays (as computed in Figs. 9c,d and 10c,d). At CSI stations 6, 9, and 15 located in 18-20 m of water depth (Fig. 16), the measured significant heights at the peak of the storm were $7 \mathrm{~m}$ (Fig. 17), and the peak periods were 12-15 s (Fig. 18). The waves began to dissipate due to depth-limited breaking before reaching these stations and gauges closer to shore. At CSI station 5 and at the AK gauges 1, 8, and 9 located 

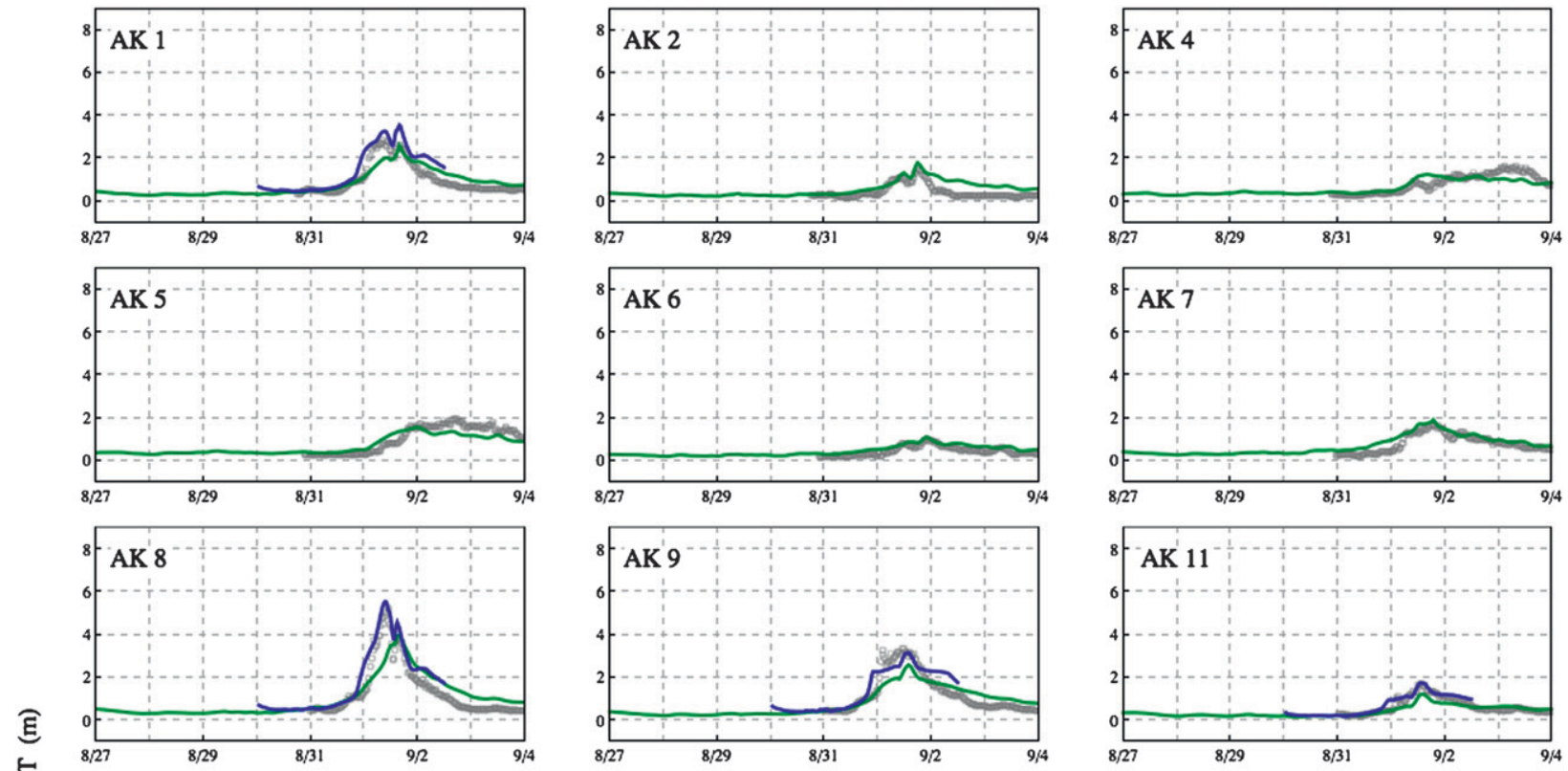

甹
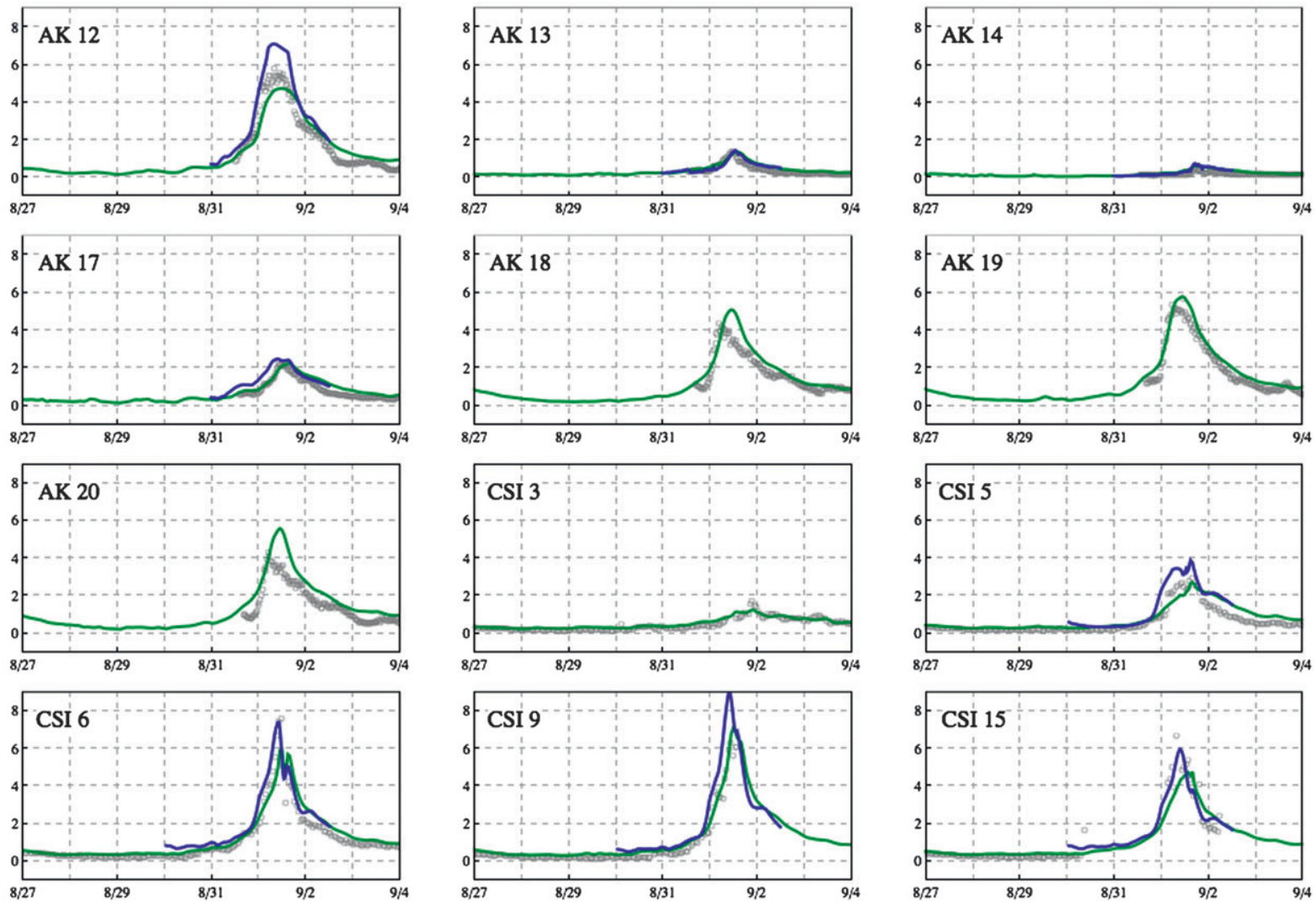

DATE IN 2008

FIG. 17. Time series of significant wave heights (m) at the 16 AK gauges and five CSI gauges shown in Fig. 16. Measured values are shown with gray circles; modeled results from SWAN (green) and STWAVE (blue) are shown with solid lines. 

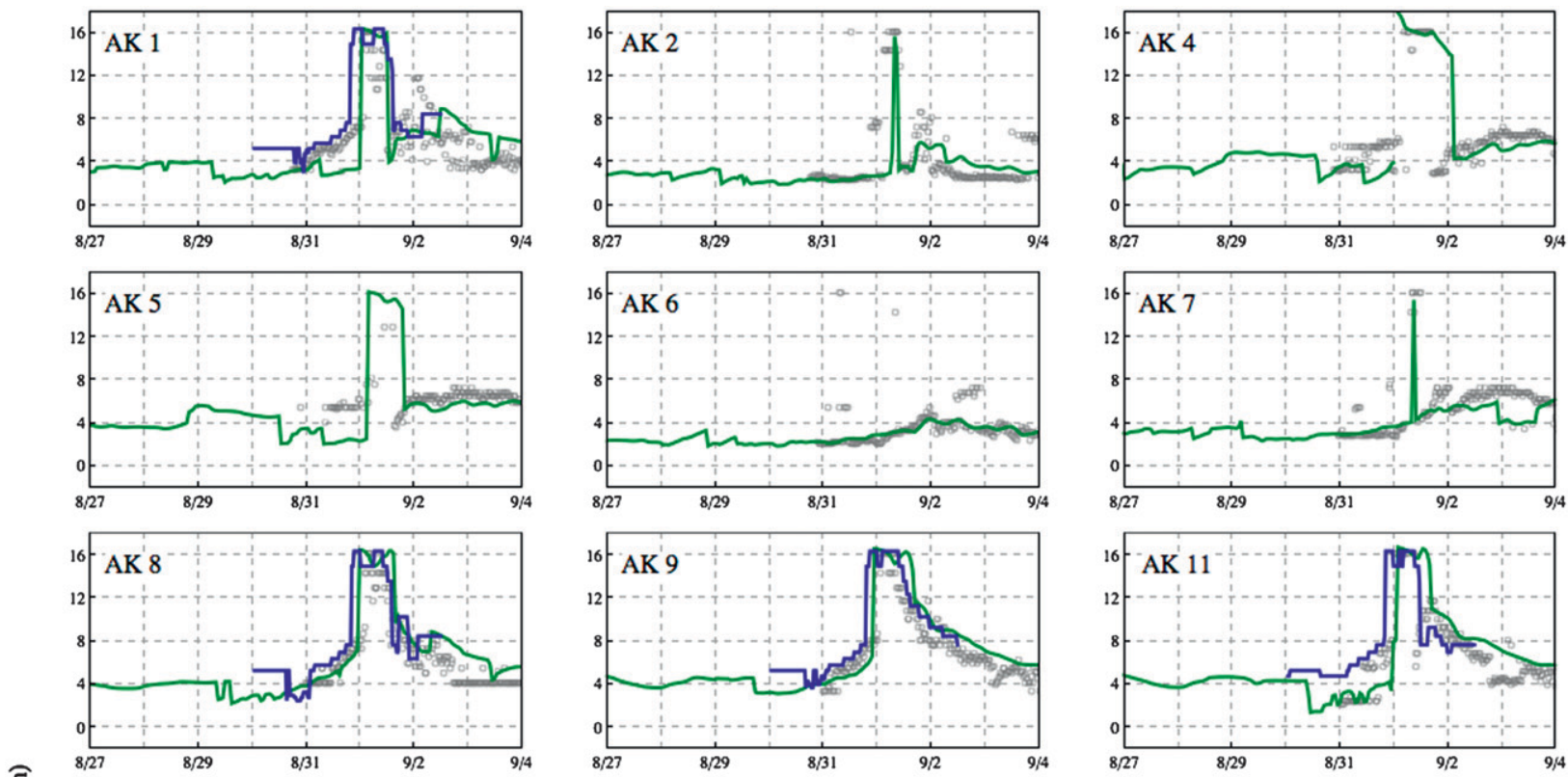

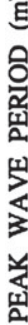
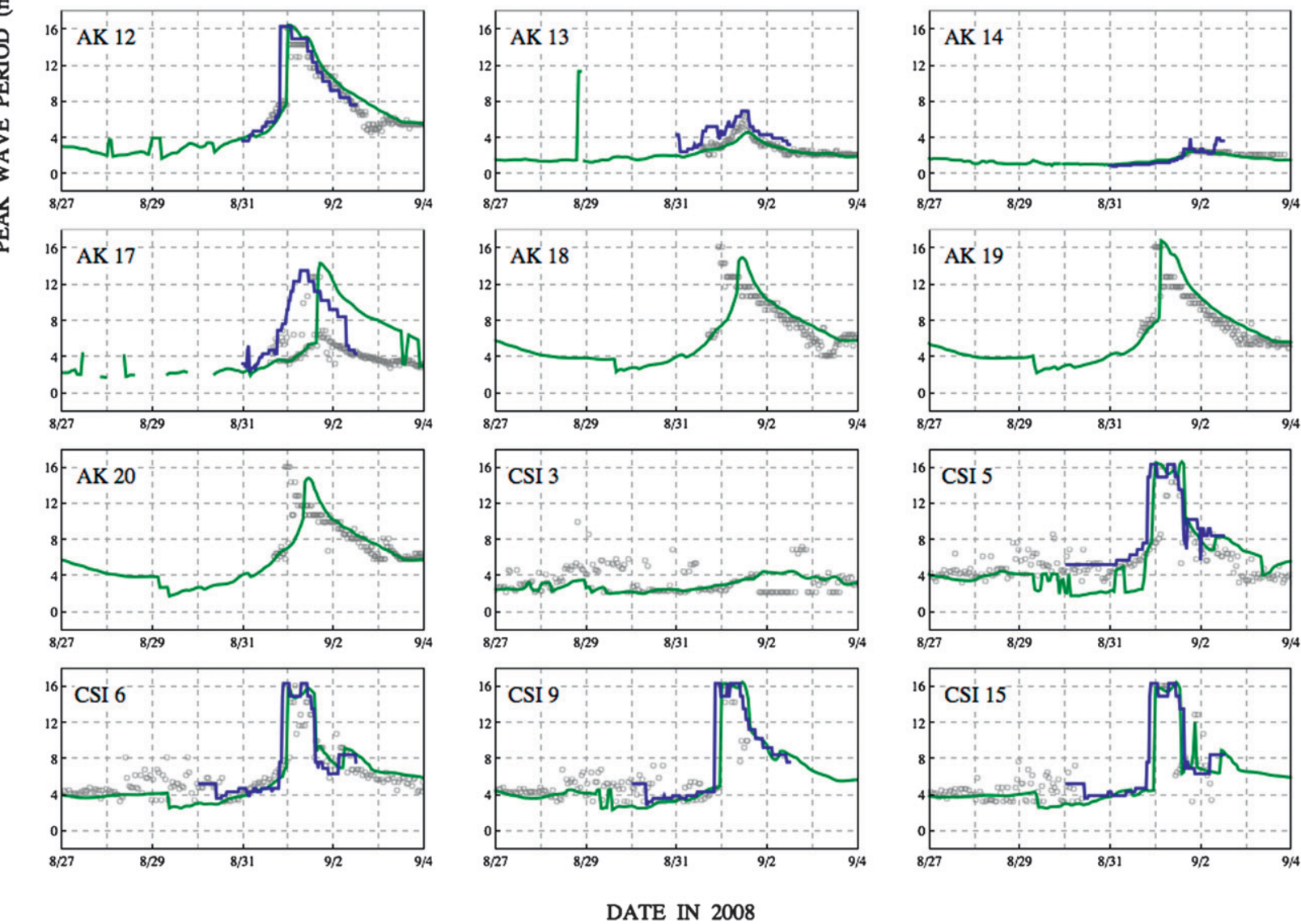

FIG. 18. As in Fig. 17, but for peak wave periods (s). 

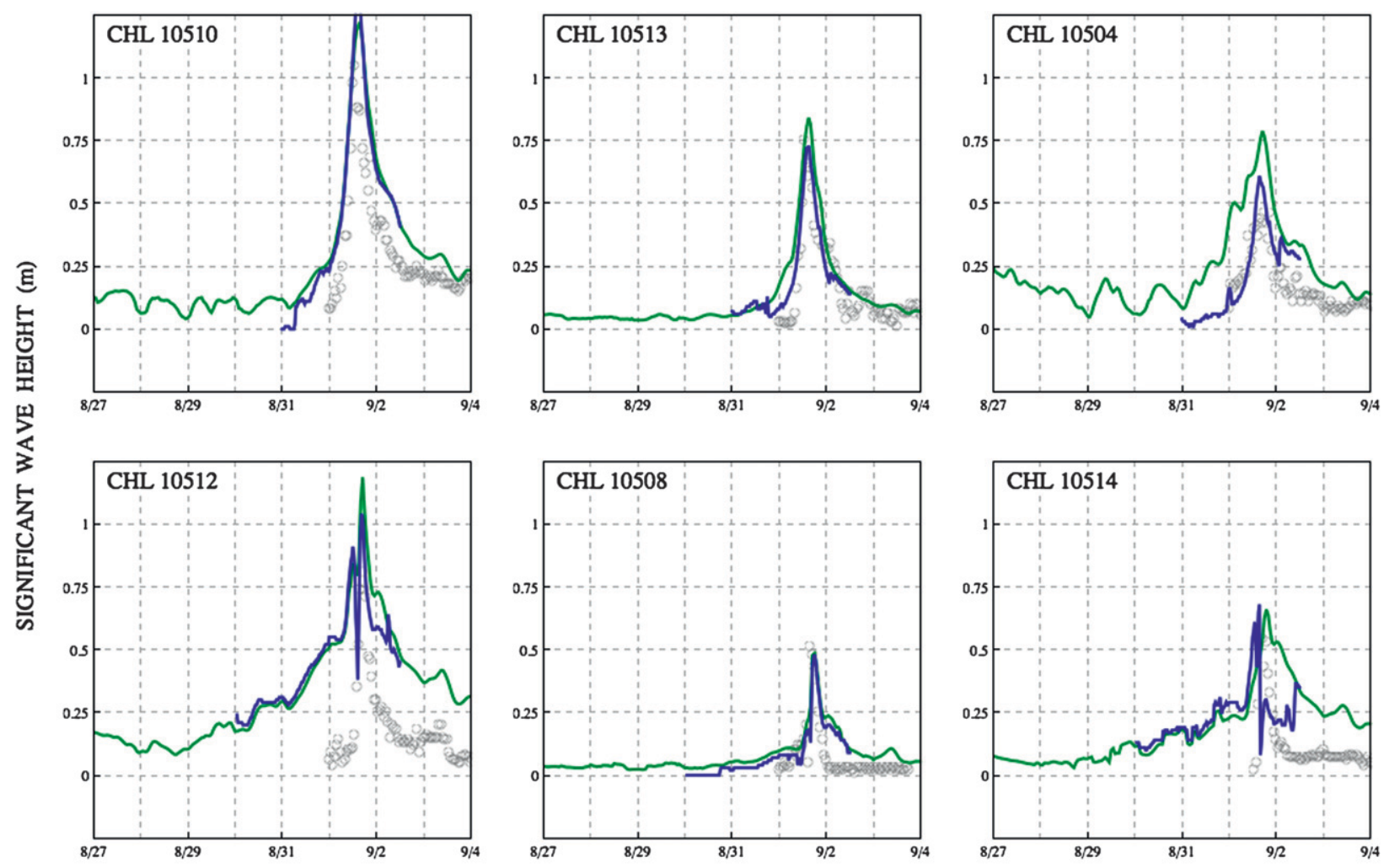

DATE IN 2008

FIG. 19. Time series of significant wave heights $(\mathrm{m})$ at the six CHL gauges shown in Fig. 16. Measured values are shown with gray circles; modeled results from SWAN (green) and STWAVE (blue) are shown with solid lines.

outside of Terrebonne Bay in 7-10 m of water depth, the peak wave heights decreased to 3-5 m. At AK gauge 11 farther east near Barataria Bay and in $3.5 \mathrm{~m}$ of water depth, the peak significant heights were $1-2 \mathrm{~m}$, and the peak periods were $16 \mathrm{~s}$. As shown in Table 5, the mean SI errors for the CSI and AK datasets are similar for STWAVE and SWAN. The mean SI errors for the significant wave heights range from 0.31 to 0.42 , while the mean SI errors for the wave periods range from 0.35 to 0.46 . The mean normalized biases for the significant wave heights range from 0.20 to 0.38 , while the mean normalized biases for the wave periods range from -0.07 to 0.27 . Dissipation of the swell and local windsea waves is captured by the measured time series and matched well by STWAVE and SWAN.

To the east of the Mississippi River, tropical-stormstrength winds pushed waves onto the LouisianaMississippi continental shelf (as computed in Figs. 9b-e and 10b-e). At NDBC buoy 42007 and AK gauge 12 located outside the Chandeleur Islands, peak waves were $6 \mathrm{~m}$, and they decreased farther east near Mobile and Pensacola Bays to $4 \mathrm{~m}$ at AK gauges 18, 19, and 20 (Figs. 16 and 17). Wave heights decreased behind the barrier islands, such as at AK gauge 17, which is located in $4.5 \mathrm{~m}$ of water depth and had a peak wave height of $2 \mathrm{~m}$.

Shoreward of the barrier islands, which attenuated the larger waves propagating onshore from open water, predominantly local waves were generated within the sounds and marshes. They generally had mean periods less than $3 \mathrm{~s}$ (as computed in Fig. 10), and their significant heights were $2 \mathrm{~m}$ in the sounds and lakes and $1 \mathrm{~m}$ or less in the wetlands (as computed in Fig. 9). Near landfall, CHL gauges 10512, 10508, and 10514 measured local wave generation and dissipation within the marshes north of Terrebonne Bay; note the decrease in the wave heights from 0.8 to $0.5 \mathrm{~m}$ at the northernmost gauges. To the east of the river, the AK gauges 13 and 14 measured 0.5- to 1-m waves over the Caernarvon marsh (Fig. 17), while the CHL gauges 10510, 10513, and 10504 measured 0.5- to 1-m waves over the Biloxi marsh (Fig. 19). The peak periods were also small in the marshes, ranging from 2 to $4 \mathrm{~s}$ at landfall (Fig. 20), although the peak periods may be underestimated because of the high-frequency cutoff of the gauges, as described above. These measurements are excellent validation tests for STWAVE and SWAN because they are located in regions with rapidly changing 

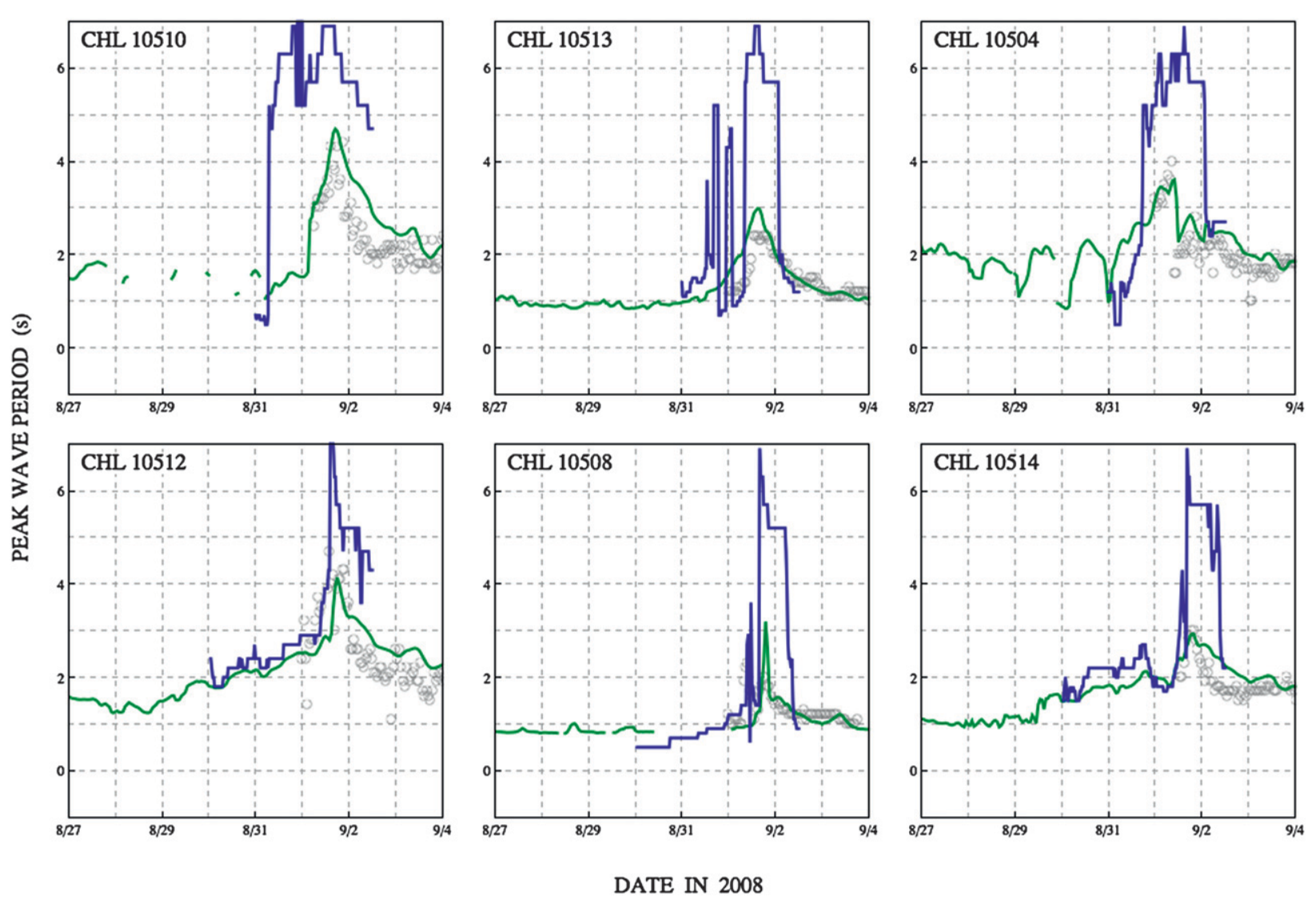

FIG. 20. As in Fig. 19, but for peak wave periods (s).

bathymetry and bottom friction. As shown in Table 5, the mean SI and mean normalized bias errors are much larger at the CHL gauges for both the SWAN and STWAVE wave models. These larger values reflect the sensitivity of the error measure to the relatively smaller wave heights and periods measured by these gauges, but they also reflect the sensitivity to bathymetric and local geometric details, the calculated surge, as well as the difficulty in parameterizing the bottom friction in these marshes. The measurements collected by these gauges are invaluable in their description of the nearshore wave environment, and they provide an opportunity for improvement of the modeled physics.

\section{c. Evolution of storm surge}

As Gustav moved through the Gulf, its easterly and southeasterly winds blew with tropical-storm strength for 12-15 h over the Louisiana-Mississippi shelf. These winds also stretched to the Florida shelf, and they helped to create a surge of $0.5-1 \mathrm{~m}$ at NOAA stations 8726724 and 8729108 (Figs. 12 and 21). Although the storm was relatively weak in intensity as it traversed the Gulf, especially compared to other Gulf storms such as Katrina and Rita, its large size caused it to impact the coastline from the Florida Keys to Texas.

During this early part of the storm, the levees of lower Plaquemines Parish experienced more than $2 \mathrm{~m}$ of surge (as computed in Figs. 11b,c). Northeasterly winds pushed water across Breton Sound and against the river levees, which are relatively unprotected by marshes in their southernmost reach. AK gauge 13 and CHL gauge 10510 are located in the wetlands near the edge of Breton Sound (Fig. 16), and they measured peak surge of 3-3.25 m (Figs. 22 and 23). The levee on the west bank in lower Plaquemines Parish extends farther south, and thus surge can enter the Mississippi River from the east and then propagate up the deep and efficient river, as shown in the gauges of the USACE (Fig. 24). At gauges south of the levees and near the delta, such as USACE gauges 1545 and 1516 , the surge was relatively small, with peaks of 1.5-2 m (Fig. 25). However, the surge was larger at the gauges upriver. At USACE gauges 1380 and 1300 in New Orleans, the peak surge was $2.5 \mathrm{~m}$ above the prestorm levels and $3 \mathrm{~m}$ relative to NAVD88 (2004.65). At USACE gauge 1220 near Donaldsonville, the surge attenuated to $2 \mathrm{~m}$ above the prestorm levels. The 

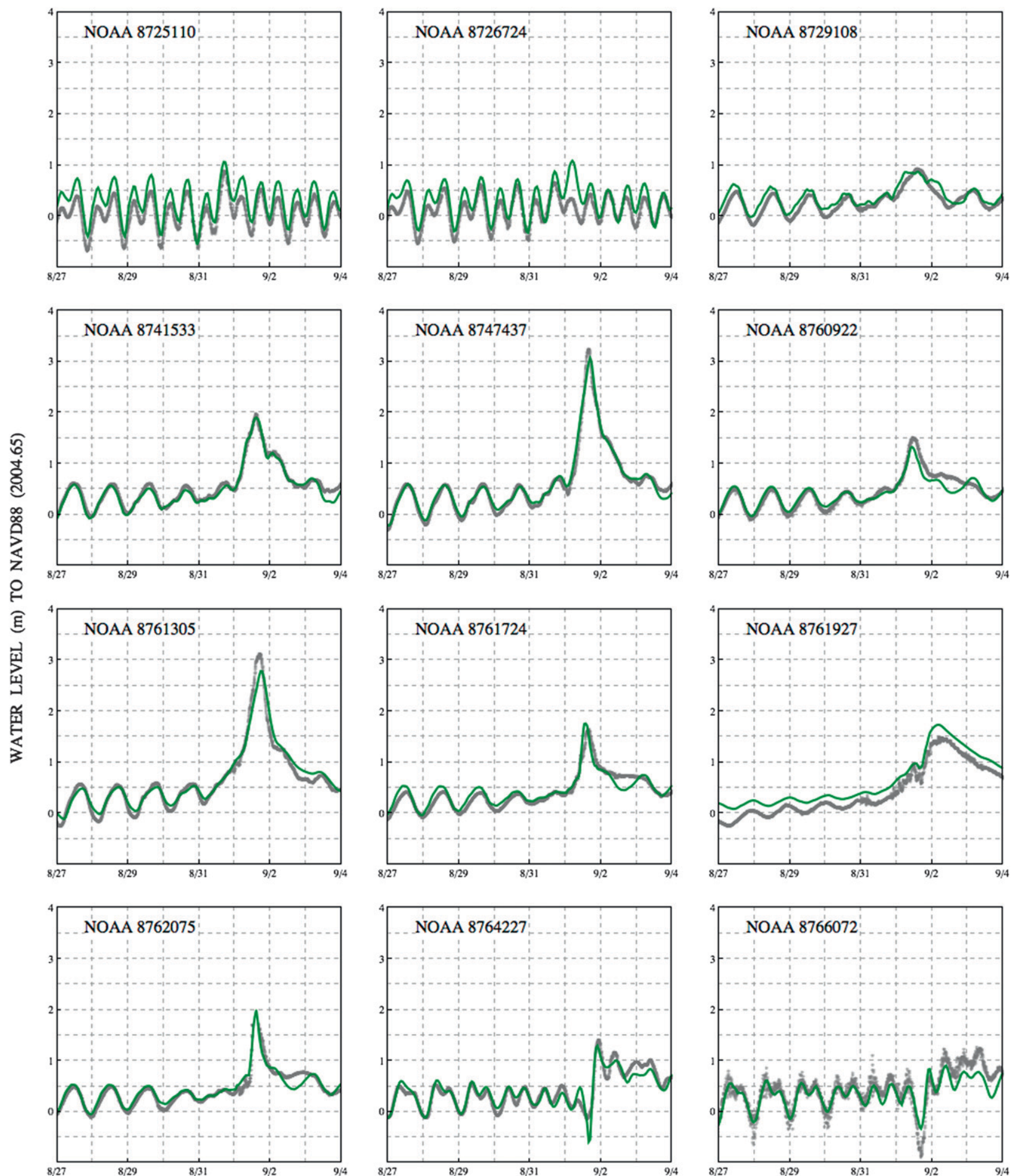

DATE IN 2008

FIG. 21. Time series of water levels (m relative to NAVD88 2004.65) at the 12 selected NOAA stations labeled in Fig. 12. Measured NOAA values are shown with gray circles; modeled ADCIRC results are shown with a green line. 

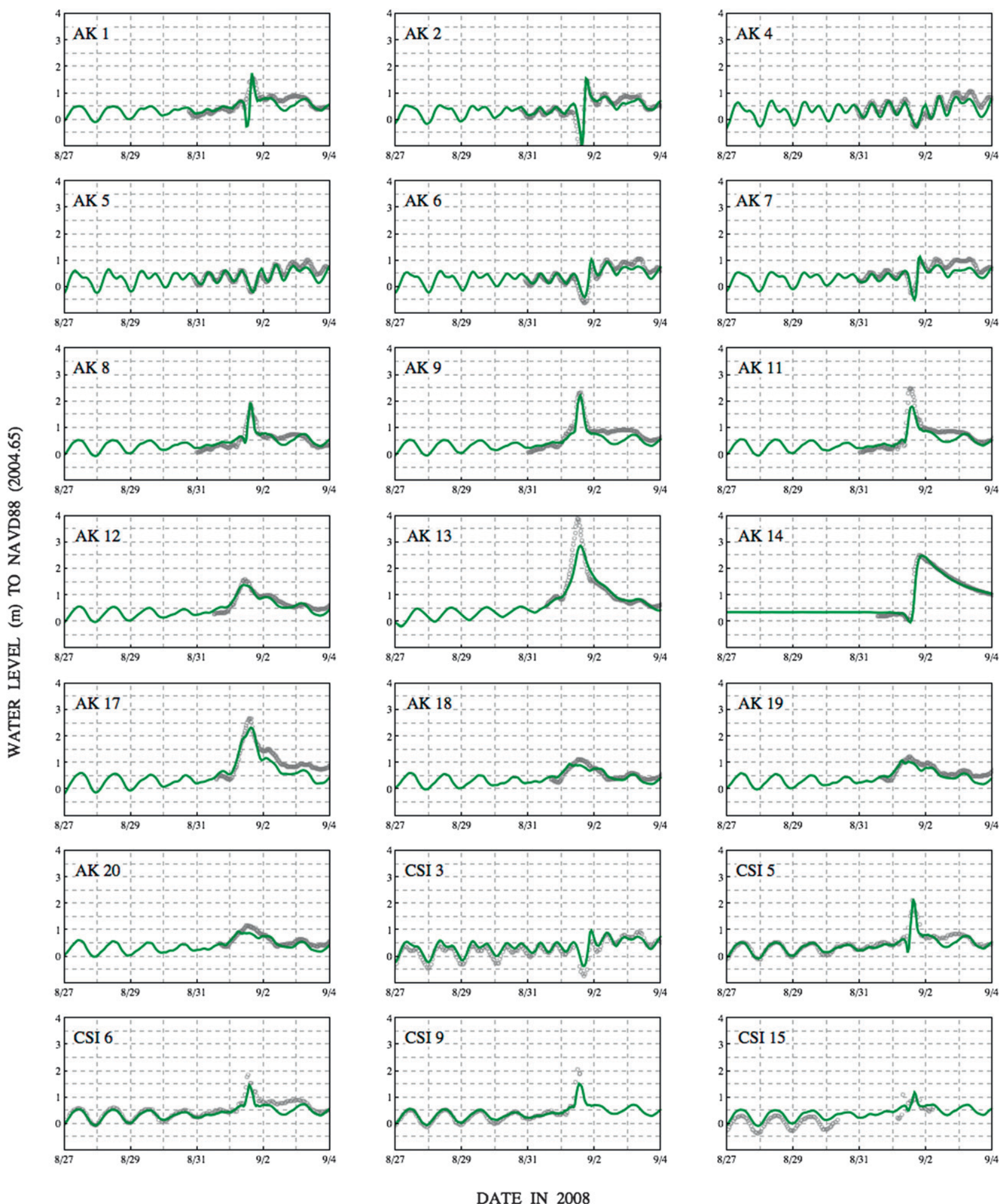

FIG. 22. Time series of water levels (m relative to NAVD88 2004.65) at the 16 AK gauges and five CSI gauges shown in Fig. 16. Measured values are shown with gray circles; modeled ADCIRC results are shown with a green line. 

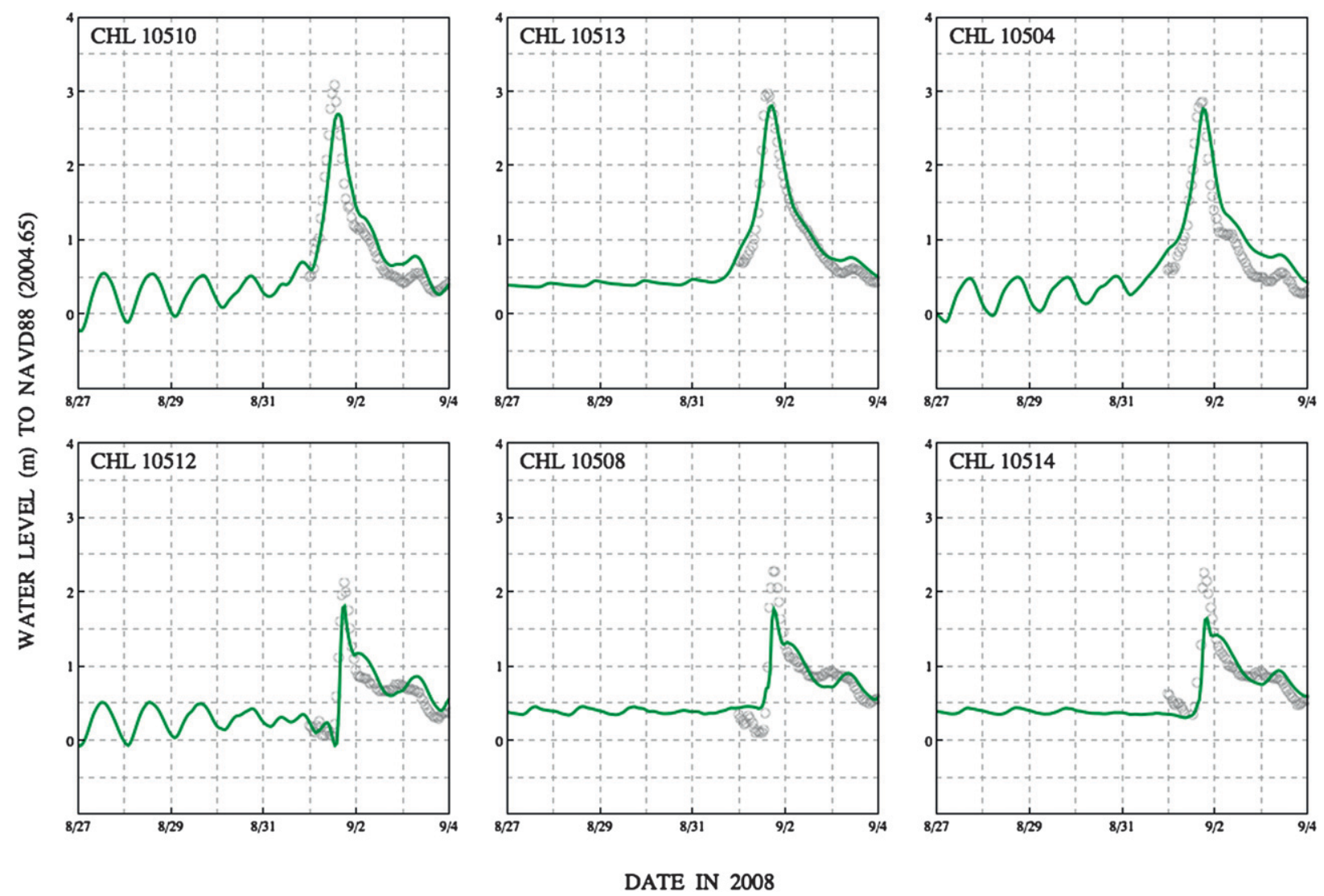

FIG. 23. Time series of water levels (m relative to NAVD88 2004.65) at the six CHL gauges shown in Fig. 16. Measured values are shown with gray circles; modeled ADCIRC results are shown with a green line.

ADCIRC model applied a constant flow rate river radiation boundary condition to the Mississippi River using an average flow value during the storm equal to $8920 \mathrm{~m}^{3} \mathrm{~s}^{-1}$. It is clear from the river hydrographs (USACE gauges 01220, 01260, 01275, 01300, 01380, and 01545 shown in Fig. 27) that the river is falling during this period and that a variable flow rate river radiation boundary condition should be used to improve model skill. It is noted that the storm period average flow rate is slightly above average for peak hurricane season. This surge did not overtop the levees along the river. However, surge would propagate similarly at higher flow rates with correspondingly higher prestorm river stages, which are possible during hurricane season.

New Orleans was also threatened by surge in the channels in and around the city. Water in Mississippi Sound and Lake Borgne was pushed by northeasterly winds into the wetlands and the confluence of the MRGO and GIWW, and eventually into the IHNC. Water levels were 2.5-3 $\mathrm{m}$ in Lake Borgne and higher in the canals (as computed in Figs. 11c,d). This relatively fast process corresponded to water being blown efficiently through Lake Borgne and to the timing of the peak winds as Gustav made landfall. At NOAA 8761305 (Fig. 21), USACE 76010 (Fig. 25), and the deployable USGS STB-04 (Fig. 27), which are located along the MRGO and the south shore of Lake Borgne, note the sharp peak of $3.25 \mathrm{~m}$ in the water levels at 1400 UTC 1 September 2008. This surge was focused by the confluence and reached higher levels of 3.5$3.75 \mathrm{~m}$ within the IHNC. This trend is shown at gauges located at the entrance to the IHNC (deployable USGS ORL-13) and within the southern reach of the IHNC (USACE 76160 and deployable USGS ORL-08). The peaks are narrow in these hydrographs, indicating that the surge enters and recedes quickly in the canal-lake-sound system. This 3.5-3.75 $\mathrm{m}$ of surge in the IHNC was a serious threat to New Orleans. The levees were not breached; however, water levels were within $0.5 \mathrm{~m}$ of the tops of the levees, and some wave overtopping was reported.

As computed in Figs. 11b-f, the Biloxi and Caernarvon marshes tend to slow the time of arrival of the surge but do not significantly attenuate the peaks thanks to the sustained northeasterly-to-southeasterly winds. The CHL gauges 10510, 10513, and 10504 show the limited dissipation of the surge as it moved over and around (through the Mississippi Sound and Lake Borgne) the 


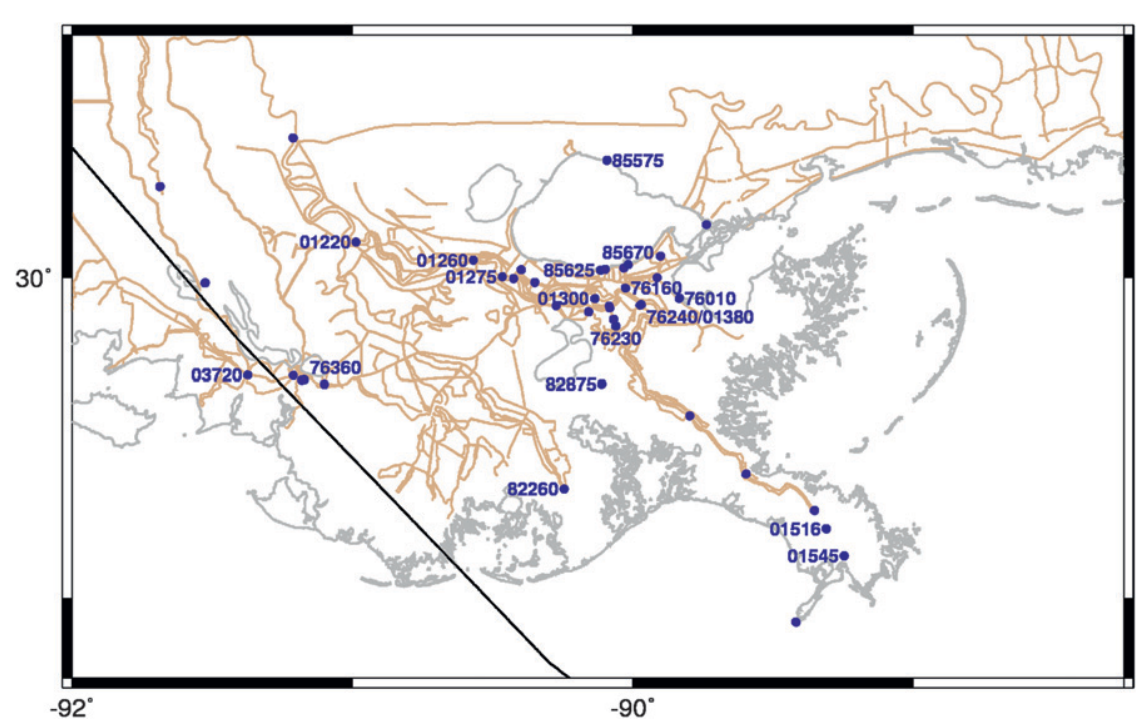

FIG. 24. Locations of the USACE water level stations (blue points) in southeastern Louisiana. The Gustav track is shown in black, the coastline and water bodies are shown in gray, and the boundaries of the SL16 mesh are shown in brown. Unlabeled USACE stations are included in the analysis in Table 6, but their time series plots are not shown in Fig. 25.

friction-dominated Biloxi marsh. Note the decrease of $0.25 \mathrm{~m}$ in the peak surge at these gauges from east to west (Fig. 23). The Caernarvon marsh also caused limited dissipation of the peak surge. At AK gauge 13 located at the edge of the marsh, the peak surge is $3.35 \mathrm{~m}$, whereas the surge is $2.25 \mathrm{~m}$ at AK gauge 14 in Lake Lery (Fig. 22). Farther north against the levees, the permanent USGS gauge 295124089542100 also shows a peak of $2.25 \mathrm{~m}$. This surge existed against the levees of lower Plaquemines Parish, prior to being pushed northward over the marsh by the shifting winds. The marshes are believed to attenuate surge by as much as $1 \mathrm{~m}$ per $14.5 \mathrm{~km}$ (USACE 1963; Resio and Westerink 2008). However, after the winds shifted, the surge pushed effectively over the marshes; note the lack of attenuation in the Caernarvon marsh 9-12 $\mathrm{h}$ after landfall (as computed in Fig. 11f). Similar to other hurricanes that have impacted the region, when Gustav's winds aligned northwestward for an extended period over the marshes, surge was pushed effectively against the levees in the vicinity of English Turn.

From the north, the city experienced surge along the levees at the south shore of Lake Pontchartrain. Before landfall, northeasterly winds pushed surge within the lake; note the northeast-to-southwest gradient in the lake in Figs. 11b,c. However, as the storm made landfall and the winds shifted, surge was pushed around the barrier islands, through Lake Borgne and the passes, and into Lake Pontchartrain. Note the surges of $2.25 \mathrm{~m}$ at AK gauge 17 (Fig. 22) and $3.25 \mathrm{~m}$ at the NOAA station 8747437 (Fig. 21) located near the entrance to Lake Borgne. This flow into the lake was caused by the easterly and southeasterly winds and by a strong gradient between the lakes (as computed in Figs. 11c-e). This exchange is shown at the permanent USGS gauges 301001089442600 and 30830089515000 in eastern Lake Pontchartrain (Fig. 26); the lake fills over the second half of 1 September 2008 and then drains gradually over 2-3 September 2008 (Fig. 27). As measured at NOAA station 8761927 (Fig. 21), the USACE gauges 85575, 85625, and 85670 (Figs. 24-26), and the deployable USGS gauges ORL-02, ORL-10, and ORL-14 (Fig. 27), the maximum surge levels in the lake were $1.5-2 \mathrm{~m}$, but they occurred 9-12 $\mathrm{h}$ after landfall, when the lake had come to an equilibrium with Lake Borgne (as computed in Fig. 11f). This behavior is matched well by ADCIRC at all gauges.

Finally, on the west bank of the river, the surge was smaller, but it propagated far inland and approached the west bank of New Orleans. As Gustav made landfall, its winds shifted southerly over Barataria Bay, creating surge of 1.5-2.25 m along Grand Isle and adjacent barrier islands (as computed in Fig. 11d). As measured at NOAA stations 8761724 and 8762075 and AK gauge 11, the coastal surge built and receded quickly. However, much of the surge pushed inland because the winds continued to blow southerly for more than $12 \mathrm{~h}$ after landfall. Surge propagated into the marsh/lake system through Little Lake, Lake Salvador, and Lake Cataouatche, located south of New Orleans. As the surge moved northward, it became less peaked in the hydrographs. At the permanent USGS gauges 292800090060000 and 07380335 located in Little Lake, the peak surge is $1.5 \mathrm{~m}$ and occurs $6-8 \mathrm{~h}$ after landfall (Fig. 27). Farther north, 

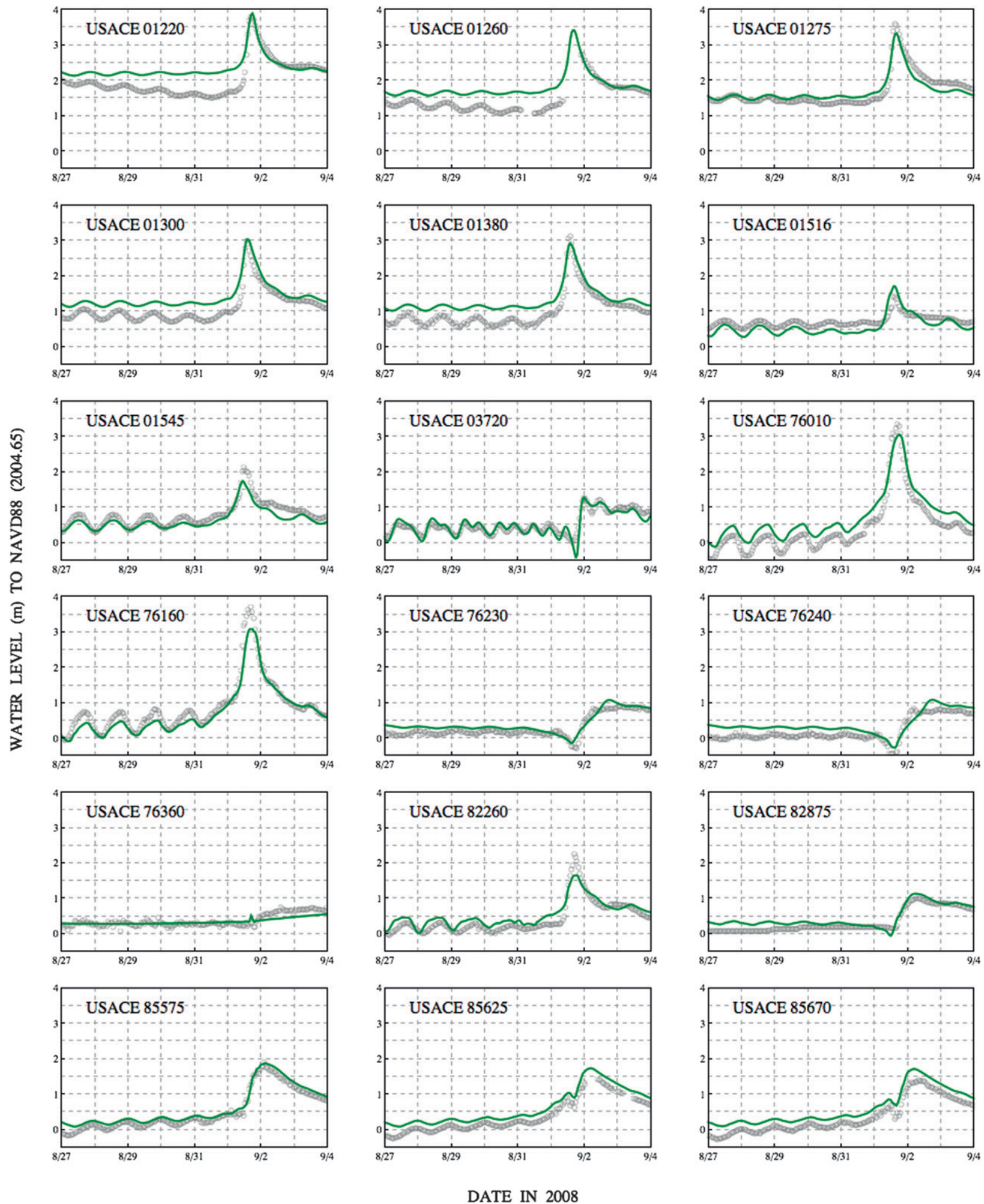

FIG. 25. Time series of water levels (m relative to NAVD88 2004.65) at the 18 selected USACE stations labeled in Fig. 24. Measured USACE values are shown with gray circles, while modeled ADCIRC results are shown with a green line. 


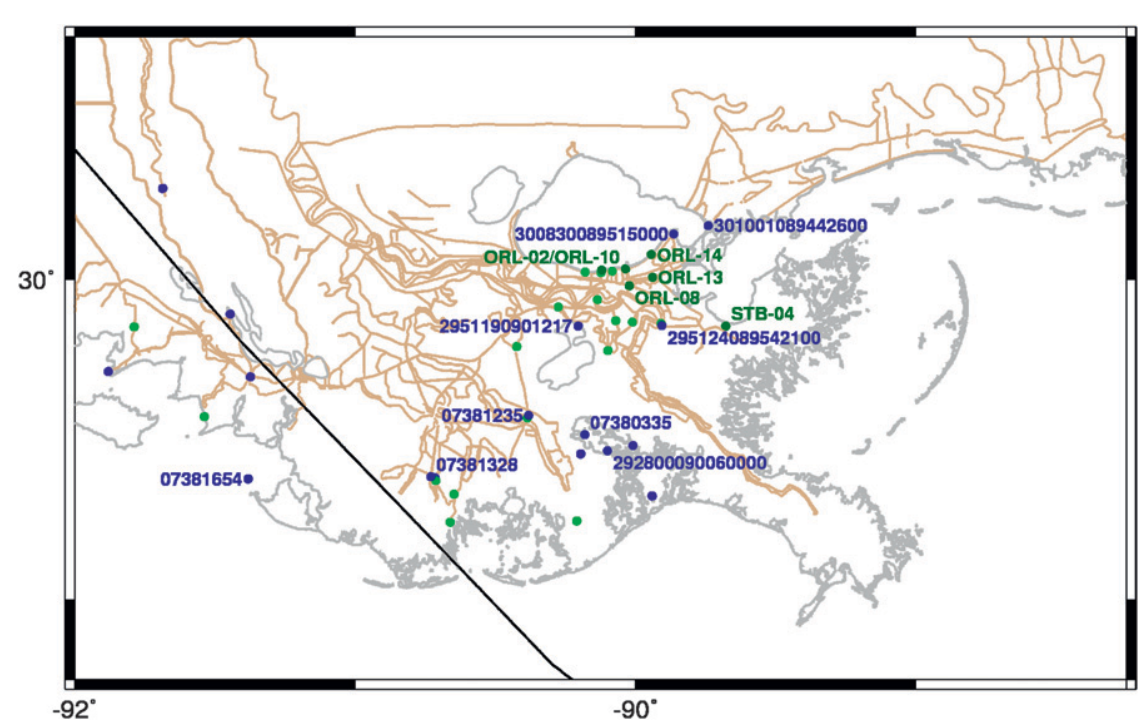

FIG. 26. Locations of the permanent USGS water level stations (blue points) and deployable USGS water level gauges (green points) in southeastern Louisiana. The Gustav track is shown in black, the coastline and water bodies are shown in gray, and the boundaries of the SL16 mesh are shown in brown. Unlabeled USGS stations are included in the analysis in Table 6, but their time series plots are not shown in Fig. 27.

at the USACE gauges 82875,76230 , and 76240 and USGS permanent gauge 2951190901217 located near Lake Salvador, the peak surge is $1 \mathrm{~m}$ and persists for 12-36 h after landfall (Fig. 25). Farther west, at the CHL gauges 10512, 10508, and 10514 located in the marsh north of Terrebonne Bay, the inland push and slow recession is also evident in the days following landfall (Fig. 23). There appears to be too much attenuation in the surge signals at CHL gauges 10508 and 10514, indicating locally insufficient resolution of finescale channels that provide conveyances that are important in getting the relatively quick surge into the system. Thus, frictional resistance and conveyance resolution are especially important when the time scale of the flow is fast.

Overall, ADCIRC correlates well to water levels throughout the region, including at most of the hydrographs herein. The mean SI errors for the time series of water levels are summarized in Table 6. The mean SI errors for the offshore (CSI and AK) and open-water (NOAA) stations and gauges range from 0.27 to 0.37 , while the mean normalized biases range from -0.04 to 0.20 . The rest of the measured time series are inland, and the mean errors are smaller at these locations, with SI ranging from 0.19 to 0.27 and normalized biases ranging from 0.04 to 0.20 . The level of skill of ADCIRC reflects the relative uncertainties of the bathymetry and bottom friction, the errors in vertical data, and the mesh resolution used to define features. Further refinement of the mesh throughout the region, especially in connection with the ever-improving input data for bathymetry, topography and land use, would continue to improve the model results. However, the overall mean SI error of 0.24 and mean normalized bias of 0.14 for the ADCIRC water levels indicates a high level of performance during this Gustav hindcast.

This behavior is confirmed by a comparison to measured HWMs from FEMA and peak values from all 365 hydrographs included in the analysis in Table 6. In Fig. 28, the points are color-coded based on the error (modeled less measured); warm colors indicate locations where ADCIRC overpredicted the peak water level, while cool colors indicate locations where ADCIRC underpredicted the peak water level. The modeled peak water levels are within $0.5 \mathrm{~m}$ at 375 of the 408 measured peaks (92\%) that were wetted by ADCIRC. In a scatterplot of measured-tomodeled peaks, the CRMS data have a best-fit slope of 0.97 and an $R^{2}$ of 0.70 , while the FEMA data have a best-fit slope of 0.94 and an $R^{2}$ of 0.82 . When all of the datasets are combined, the best-fit line has a slope of 0.95 and $R^{2}$ of 0.81, as shown in Fig. 29. Some portion of these differences can be attributed to measurement error, which is quantified using an estimation method described by Bunya et al. (2010). When the measurement error is taken into account (Table 6), the average absolute ADCIRC error is $0.14 \mathrm{~m}$, and the standard deviation is $0.22 \mathrm{~m}$.

This level of model skill can be attributed to the mesh resolution of the SL16 mesh and the representation of detailed features, but it is also a result of the wave-current interaction and the resulting wave-induced setup. Figure 30 

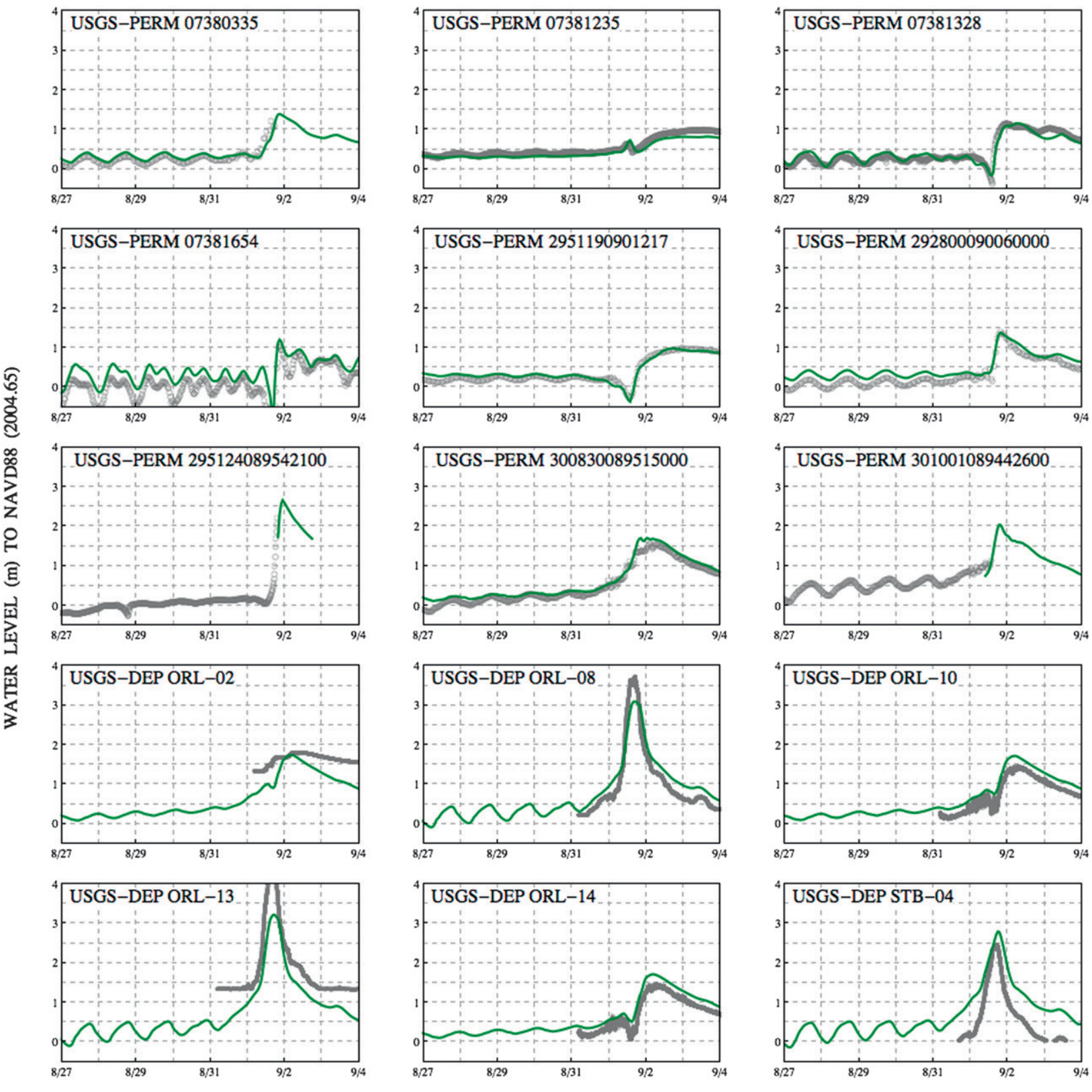

DATE IN 2008

FIG. 27. Time series of water levels (m relative to NAVD88 2004.65) at the selected nine permanent USGS stations and six deployable USGS gauges labeled in Fig. 26. Measured USGS values are shown with gray circles, and modeled ADCIRC results are shown with a green line.

shows the wave-induced water level setup resulting from coupling STWAVE and ADCIRC and coupling SWAN and ADCIRC. The STWAVE and SWAN models generally lead to very similar wave-induced setup as large as $0.5 \mathrm{~m}$ for Gustav. Behind the breaking zones, the waveinduced setup from both models accounts for $0.1-0.3 \mathrm{~m}$ throughout much of the region, and $0.5 \mathrm{~m}$ in regions near the high-gradient shallow-water wave dissipation zones.
These contributions can be locally significant when compared to the overall peak water levels, which were $2-3 \mathrm{~m}$ in the marshes and lakes behind the barrier islands. Differences between the STWAVE and SWAN model couplings to ADCIRC are attributable to the wave model domain extent, grid resolution, and most importantly to the way in which waves are dissipated. Wave dissipation in STWAVE is more localized, leading to a more rapid spatial gradient in 
TABLE 6. Summary of errors for the ADCIRC water levels at all of the circulation datasets. The mean SI and mean normalized errors were computed only for the time series data, so there are no reported mean errors for the URS/FEMA HWM dataset. The average absolute differences, average absolute error, and standard deviations have units of meters. The measurement errors require the HWM locations to be clustered geographically and hydraulically, and thus they could not be computed for five of the sparser datasets.

\begin{tabular}{|c|c|c|c|c|c|c|c|c|c|c|c|}
\hline \multirow[b]{3}{*}{ Dataset } & \multirow{3}{*}{$\begin{array}{l}\text { No. of } \\
\text { locations }\end{array}$} & \multirow[b]{3}{*}{ SI } & \multirow[b]{3}{*}{ Bias } & & & \multicolumn{2}{|c|}{$\begin{array}{c}\text { ADCIRC to } \\
\text { measured HWMs }\end{array}$} & \multicolumn{2}{|c|}{$\begin{array}{l}\text { Measured } \\
\text { HWMs }\end{array}$} & \multicolumn{2}{|c|}{$\begin{array}{c}\text { Estimated } \\
\text { ADCIRC errors }\end{array}$} \\
\hline & & & & \multicolumn{2}{|c|}{ Best fit } & Avg absolute & & Avg absolute & & Avg absolute & \\
\hline & & & & Slope & $R^{2}$ & diff & Std dev & diff & Std dev & error & Std dev \\
\hline CSI & 5 & 0.37 & 0.19 & 0.904 & 0.622 & 0.238 & 0.303 & - & - & - & - \\
\hline $\mathrm{AK}$ & 16 & 0.27 & -0.04 & 0.882 & 0.828 & 0.149 & 0.171 & 0.030 & 0.049 & 0.119 & 0.164 \\
\hline NOAA & 23 & 0.29 & 0.20 & 0.978 & 0.910 & 0.170 & 0.206 & - & - & - & - \\
\hline $\mathrm{CHL}$ & 6 & 0.23 & 0.04 & 0.882 & 0.826 & 0.327 & 0.199 & - & - & - & - \\
\hline USACE & 39 & 0.24 & 0.10 & 0.944 & 0.893 & 0.281 & 0.314 & 0.095 & 0.195 & 0.186 & 0.246 \\
\hline USGS (Perm) & 18 & 0.19 & 0.09 & 1.038 & 0.830 & 0.184 & 0.241 & - & - & - & - \\
\hline USGS (Depl) & 24 & 0.27 & 0.20 & 0.968 & 0.761 & 0.260 & 0.317 & - & - & - & - \\
\hline CRMS & 232 & 0.23 & 0.15 & 0.969 & 0.704 & 0.177 & 0.223 & 0.049 & 0.097 & 0.128 & 0.201 \\
\hline FEMA & 82 & - & - & 0.937 & 0.825 & 0.223 & 0.240 & 0.046 & 0.083 & 0.177 & 0.226 \\
\hline All & 444 & 0.24 & 0.14 & 0.952 & 0.807 & 0.216 & 0.280 & 0.064 & 0.139 & 0.142 & 0.220 \\
\hline
\end{tabular}

wave heights and higher peak wave radiation stress gradients in shallower depths. The peaks in its setup are therefore larger in the vicinity of the Chandeleur Islands and the Mississippi River delta. SWAN spreads its dissipation over a larger area.

\section{Conclusions}

Gustav made landfall as a category 2 storm at Cocodrie, Louisiana, and near Terrebonne Bay in southern Louisiana. Its strongest winds were concentrated west of the Mississippi River, and its largest waves dissipated along the delta and continental shelf break. However, because of its large size, the hurricane blew strong winds over the Louisiana-Mississippi shelf, pushing surge through the Mississippi Sound and Lake Borgne, over the marshes and against the levee system of metropolitan New Orleans. The highest water levels were observed in the channels near the city, and levees were threatened with overtopping and breaching. New Orleans was protected by its levees, the marshes to the south and east, the relative weakness of the storm, and the distance from landfall. Nevertheless, Gustav created significant surge on all sides of the city.

An unprecedented amount of wave and water level information was collected for Hurricane Gustav, and, together with high-quality data-assimilated winds, they

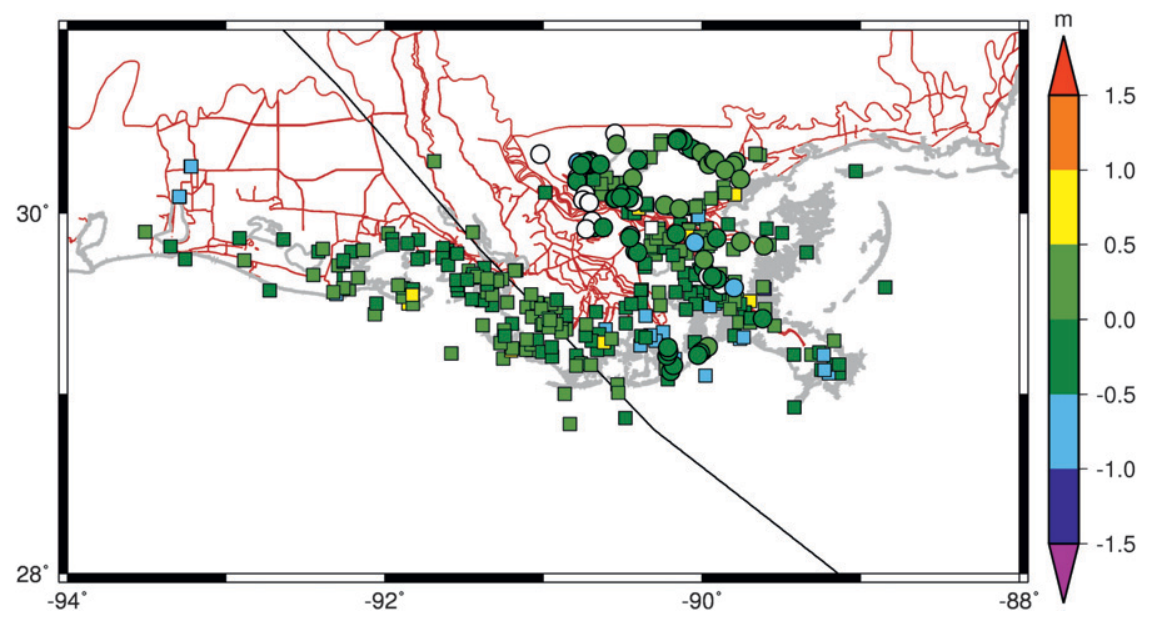

FIG. 28. Locations of the 82 URS/FEMA HWMs (circles) and 362 hydrographs (squares) in southeastern Louisiana. The points are color-coded to show the errors (modeled less measured) between the peak water levels; green points indicate matches within $0.5 \mathrm{~m}$. Warm colors indicate locations where ADCIRC overpredicted the peak water level, while cool colors indicate locations where ADCIRC underpredicted the peak water level. White points indicate locations that were never wetted by ADCIRC. 


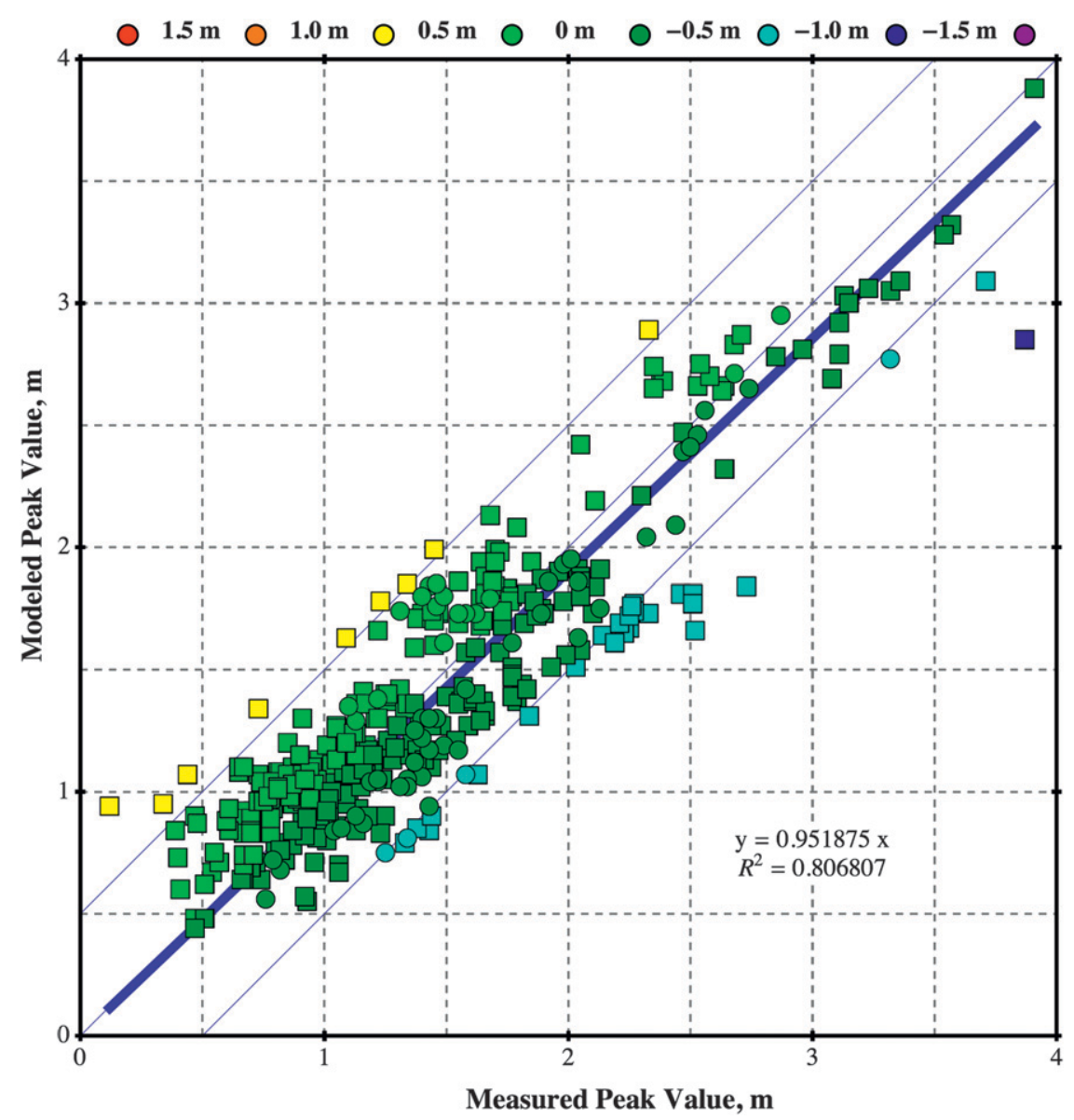

FIG. 29. Scatterplot of FEMA HWMs (circles) and peak hydrograph water levels (squares) for Gustav. Green points indicate a match within $0.5 \mathrm{~m}$. Red, orange, yellow, and light green circles indicate overprediction by the model; green, blue, dark blue, and purple circles indicate underpredictions. The slope of the best-fit line through all points is 0.95 and the $R^{2}$ value is 0.81 .

allow for a thorough assessment of the performance of the WAM, STWAVE, SWAN, and ADCIRC models in simulating the physics of hurricane waves and surge from the deep Gulf of Mexico to the inland portions of the coastal floodplain. It is especially important that most of this data is in the form of time histories, which allow for an evaluation of the durations and timing of processes, and thus an understanding of the frictional dynamics of process propagation, attenuation, and/or recession.

As Gustav moved in deep water, it created large waves that radiated outward and impacted most of the Gulf. The waves had estimated significant heights of $15 \mathrm{~m}$ nearer to the storm's track. NDBC buoys measured waves with significant heights of $8-10 \mathrm{~m}$, and the timing and magnitudes of these waves are matched well by WAM and SWAN. In shallow water, the nearshore instruments of CSI platforms and AK buoys measured the waves as they were dissipated on the continental shelf. Waves were further dissipated by the barrier islands, and predominantly local waves were generated and dissipated in the marshes, as shown by the gauges of AK and CHL. Overall, as shown in Table 5, the three wave models perform similarly with respect to their mean SI and mean normalized bias errors. In the Gulf of Mexico deep and shelf waters, WAM overall performed slightly better for significant wave heights while SWAN produces a smaller mean SI and mean normalized bias for peak and mean wave periods. For this storm, WAM simulates better significant wave heights for the short duration, lower energy swell for the NDBC buoys at the edge of the Texas shelf. Inner-shelf, open-water wave characteristics are similarly and generally well modeled by STWAVE and SWAN. Further work is necessary to determine propagation and dissipation characteristics for swell onto and across shelves, as well as across rapid topographic transitions such as barrier islands, by looking at a range of storms and by collecting additional wave data in the vicinity of these features. This will improve 

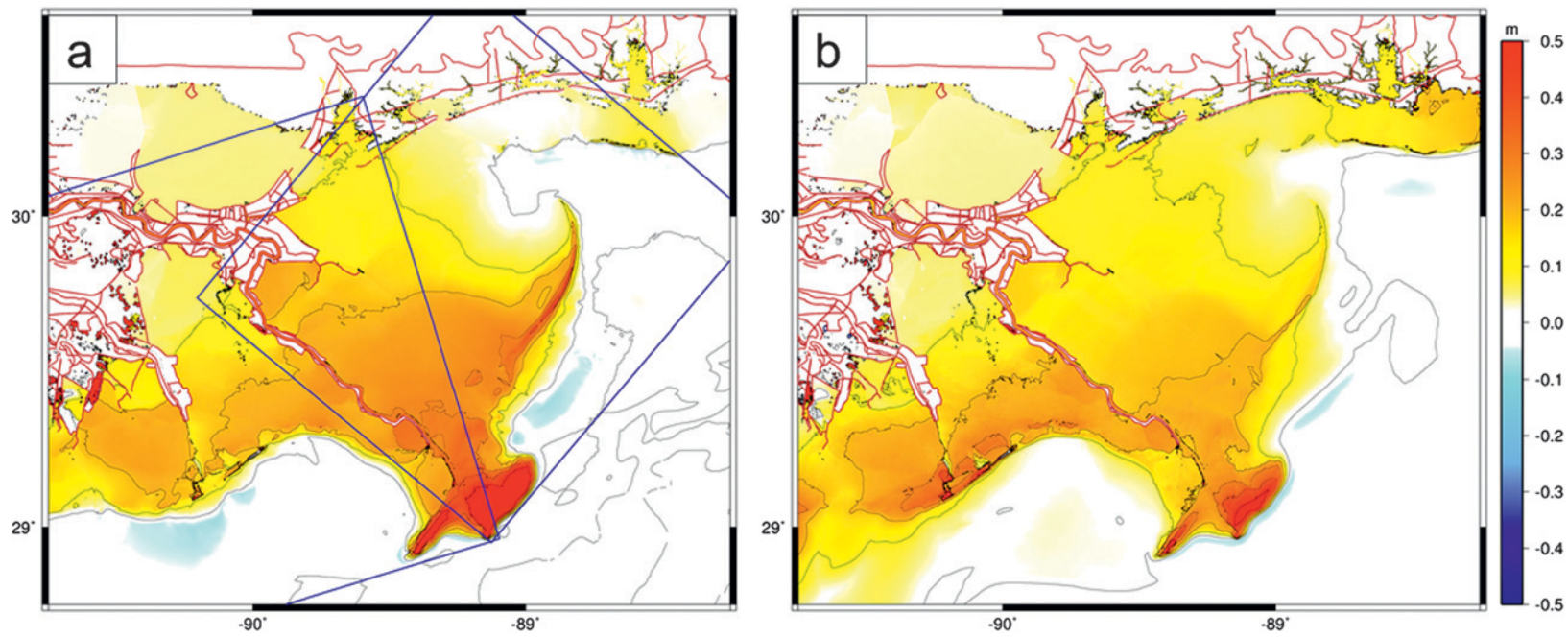

FIG. 30. Maximum Gustav event wave-induced setup produced by coupling ADCIRC to (a) STWAVE and (b) SWAN. The extents of the two structured STWAVE domains are shown in blue lines.

our understanding of wave transformation as well as wave radiation stress gradients in shallow water, which in turn drive coastal wave-induced setup and currents. Improved accuracy of bathymetry/topography and the associated mesh resolution will also help improve wave modeling skill, particularly in shallow waters where depth-limited breaking dominates. Presently, many parts of coastal Louisiana are still very poorly surveyed, with many bathymetric values dating back more than 50 years. At the marsh locations measured by the CHL gauges, the mean SI and mean normalized bias errors are large for both STWAVE and SWAN, indicating that both models require further work to improve their bottom friction and dissipation through porous wetlands systems.

Gustav's large size caused its tropical-storm-strength winds to impact the region for 12-15 h before and during landfall, and these winds pushed surge across the LouisianaMississippi shelf and against the levees of lower Plaquemines Parish. Surge of $2-2.75 \mathrm{~m}$ above the prestorm levels was pushed up the Mississippi River, and surge of 3-3.5 $\mathrm{m}$ was pushed into the IHNC. The peak surge occurred east of the river, in regions where the maximum winds did not reach, because the storm was large enough in size to blow medium-strength winds over the shelf for an extended length of time. In Lake Pontchartrain, water levels increased to $1.5-2 \mathrm{~m}$ as surge was pushed through the Rigolets and Chef Menteur passes. To the southwest, the Caernarvon and Biloxi marshes are widely believed to attenuate storm surge by as much as $3 \mathrm{~m}$, but the surge from the levees along lower Plaquemines Parish was pushed northward effectively over the marshes and against the levees near Braithwaite and English Turn. The marshes offered little protection as the water levels were within $0.5 \mathrm{~m}$ of the tops of the levees. Finally, the interconnected marshes south and west of New Orleans allowed storm surge to propagate from the landfall location and threaten the city many hours after the storm passed. Surge of $0.75-1 \mathrm{~m}$ was observed on the west bank even 12-36 $\mathrm{h}$ after landfall.

The storm surge is also described by a wealth of measured water level data, and ADCIRC correlates well with its water levels. The overall mean SI error was 0.24 and mean normalized bias was 0.14 at 362 measurement locations, and the modeled peak water levels were within $0.5 \mathrm{~m}$ at $92 \%$ of the HWMs and peak hydrograph values. The timing of peaks, rise rates, and recession rates were captured well by ADCIRC. This level of model skill results from the increased resolution of the SL16 mesh, which represents small-scale channels and conveyances as well as the use of spatially varying Manning's $n$-based friction. Improvements in modeling inland surge can be achieved by developing a time-dependent river radiation boundary condition to allow for time-varying river inflows, further refining flow conveyances penetrating into the floodplain, and perfecting the representation of wetland friction to consider the complex finescale channels as well as the change in character that occurs during a storm including considering the transition from emergent to submerged and the flattening of wetland grasses as the storm progresses.

Acknowledgments. This work was supported by the U.S. Army Corps of Engineers (USACE) New Orleans District and the Federal Emergency Management Agency Region 6. Computational resources and support were provided by the U.S. Army Engineer Research and 
Development Center, Department of Defense Supercomputing Resource Center and the University of Texas at Austin, Texas Advanced Computing Center. Awards from the National Science Foundation (OCI0746232) and the Office of Naval Research (N0001406-1-0285) supported ADCIRC and SWAN model development. Permission to publish this paper was granted by the Chief of Engineers, U.S. Army Corps of Engineers. This material is based upon work supported by the U.S. Department of Homeland Security under Award 2008-ST-061-ND0001. The views and conclusions contained in this document are those of the authors and should not be interpreted as necessarily representing the official policies, either expressed or implied, of the U.S. Department of Homeland Security.

\section{REFERENCES}

Amante, C., and B. W. Eakins, 2009: ETOPO1 1 arc-minute global relief model: Procedures, data sources and analysis. NOAA Tech. Memo. NESDIS NGDC-24, 19 pp.

Battjes, J. A., and J. P. F. M. Janssen, 1978: Energy loss and set-up due to breaking of random waves. Proc. 16th Int. Conf. on Coastal Engineering, ASCE, Hamburg, Germany, 569-587.

Beven, J. L., and T. B. Kimberlain, 2009: Tropical Cyclone Report, Hurricane Gustav, 25 August-4 September 2009. NOAA/ National Hurricane Center, 38 pp. [Available online at http:// www.nhc.noaa.gov/ms-word/TCR-AL072008_Gustav.doc.]

Booij, N., R. C. Ris, and L. H. Holthuijsen, 1999: A third-generation wave model for coastal regions. 1. Model description and validation. J. Geophys. Res., 104, 7649-7666.

Bretschneider, C. L., H. J. Krock, E. Nakazaki, and F. M. Casciano, 1986: Roughness of typical Hawaiian terrain for tsunami runup calculations: A user's manual. J. K. K. Look Laboratory Report, University of Hawaii, 42 pp.

Buczkowski, B. J., J. A. Reid, C. J. Jenkins, J. M. Reid, S. J. Williams, and J. G. Flocks, cited 2006: usSEABED: Gulf of Mexico and Caribbean (Puerto Rico and U.S. Virgin Islands) offshore surficial sediment data release. U.S. Geological Survey Data Series 146, version 1.0. [Available online at http://pubs.usgs. gov/ds/2006/146/.]

Bunya, S., and Coauthors, 2010: A high-resolution coupled riverine flow, tide, wind, wind wave, and storm surge model for southern Louisiana and Mississippi. Part I: Model development and validation. Mon. Wea. Rev., 138, 345-377.

Cardone, V. J., 1969: Specification of the wind distribution in the marine boundary layer for wave forecasting. Tech. Rep. 69-1, Geophysical Sciences Laboratory, New York University, $131 \mathrm{pp}$.

—_, and A. T. Cox, 2007: Tropical cyclone wind field forcing for surge models: Critical issues and sensitivities. Nat. Hazards, 51, 29-47.

Cox, A. T., J. A. Greenwood, V. J. Cardone, and V. R. Swail, 1995: An interactive objective kinematic analysis system. Proc. Fourth Int. Workshop on Wave Hindcasting and Forecasting, Banff, AB, Canada, Atmospheric Environment Service, 109-118.

Dawson, C., J. J. Westerink, J. C. Feyen, and D. Pothina, 2006: Continuous, discontinuous and coupled discontinuouscontinuous Galerkin finite element methods for the shallow water equations. Int. J. Numer. Methods Fluids, 52, 63-88.
Dietrich, J. C., and Coauthors, 2010: A high-resolution coupled riverine flow, tide, wind, wind wave and storm surge model for southern Louisiana and Mississippi. Part II: Synoptic description and analysis of Hurricanes Katrina and Rita. Mon. Wea. Rev., 138, 378-404.

_ - and Coauthors, 2011: Modeling hurricane waves and storm surge using integrally-coupled, scalable computations. Coastal Eng., 58, 45-65, doi:10.1016/j.coastaleng.2010.08.001.

Ebersole, B. A., J. J. Westerink, D. T. Resio, and R. G. Dean, 2007: Performance evaluation of the New Orleans and Southeast Louisiana Hurricane Protection System. Volume IV: The storm. Final Report of the Interagency Performance Evaluation Task Force, U.S. Army Corps of Engineers, Washington, DC, 263 pp.

FEMA, 2009a: Flood insurance study: Southeastern parishes, Louisiana-Intermediate submission 2: Offshore water levels and waves. U.S. Army Corps of Engineers, New Orleans District, $192 \mathrm{pp}$.

2009b: Louisiana Hurricane Ike coastal high water mark data collection. February 2009 draft report FEMA-1792-DRLouisiana, $249 \mathrm{pp}$.

Garster, J. K., B. Bergen, and D. Zilkoski, 2007: Performance evaluation of the New Orleans and Southeast Louisiana Hurricane Protection System, Volume II-Geodetic vertical and water level datums. Final Report of the Interagency Performance Evaluation Task Force, U.S. Army Corps of Engineers, 157 pp.

Günther, H., 2005: WAM cycle 4.5 version 2.0. Institute for Coastal Research, GKSS Research Centre, Geesthacht, Germany, 38 pp.

Hanson, J. L., B. A. Tracy, H. L. Tolman, and R. D. Scott, 2009: Pacific hindcast performance of three numerical wave models. J. Atmos. Oceanic Technol., 26, 1614-1633.

Hasselmann, S., K. Hasselmann, J. H. Allender, and T. P. Barnett, 1985: Computations and parameterizations of the nonlinear energy transfer in a gravity-wave spectrum. Part II: Parameterizations of the nonlinear transfer for application in wave models. J. Phys. Oceanogr., 15, 1378-1391.

Holland, G., 1980: An analytic model of the wind and pressure profiles in hurricanes. Mon. Wea. Rev., 108, 1212-1218.

Janssen, P. A. E. M., 1991: Quasi-linear theory of wind-wave generation applied to wave forecasting. J. Phys. Oceanogr., 21, 1631-1642.

Kennedy, A. B., and Coauthors, 2010: Rapidly installed temporary gauging for waves and surge during Hurricane Gustav. Cont. Shelf Res., 30, 1743-1752.

— , and Coauthors, 2011: Origin of the Hurricane Ike forerunner surge. Geophys. Res. Lett., 38, L08608, doi:10.1029/2011GL047090.

Knabb, R. D., J. R. Rhome, and D. P. Brown, 2005: Tropical cyclone report, Hurricane Katrina, 23-30 August 2005. NOAA/ National Hurricane Center, 43 pp. [Available online at http:// www.nhc.noaa.gov/pdf/TCR-AL122005_Katrina.pdf.]

Kolar, R. L., J. J. Westerink, M. E. Cantekin, and C. A. Blain, 1994: Aspects of nonlinear simulations using shallow water models based on the wave continuity equations. Comput. Fluids, 23, 523-538.

Komen, G., L. Cavaleri, M. Donelan, K. Hasselmann, S. Hasselmann, and P. A. E. M. Janssen, 1994: Dynamics and Modeling of Ocean Waves. Cambridge University Press, 560 pp.

Luettich, R. A., and J. J. Westerink, 2004: Formulation and numerical implementation of the 2D/3D ADCIRC finite element model version 44.XX, 74 pp. [Available online at http:// adcirc.org/adcirc_theory_2004_12_08.pdf.]

Madsen, O. S., Y.-K. Poon, and H. C. Graber, 1988: Spectral wave attenuation by bottom friction: Theory. Proc. 21st Int. Conf. on Coastal Engineering, ASCE, 492-504. 
NOAA, cited 2008: National Geophysical Data Center Coastal Relief Model. [Available online at http://www.ngdc.noaa.gov/ $\mathrm{mgg} /$ coastal/coastal.html.]

Powell, M. D., 2006: Drag coefficient distribution and wind speed dependence in tropical cyclones. Final report to the NOAA Joint Hurricane Testbed (JHT) Program, 26 pp.

—, and T. A. Reinhold, 2007: Tropical cyclone destructive potential by integrated kinetic energy. Bull. Amer. Meteor. Soc., 88, 513-526.

— S. Houston, and T. Reinhold, 1996: Hurricane Andrew's landfall in South Florida. Part I: Standardizing measurements for documentation of surface wind fields. Wea. Forecasting, 11, 304-328.

- — L L. Amat, and N. Morrisseau-Leroy, 1998: The HRD real-time hurricane wind analysis system. J. Wind Eng. Ind. Aerodyn., 77-78, 53-64.

— P. J. Vickery, and T. A. Reinhold, 2003: Reduced drag coefficient for high wind speeds in tropical cyclones. Nature, 422, 279-283.

— wind fields for storm surge and wave hindcasting. Ocean Eng., 37, 26-36.

Resio, D. T., and J. J. Westerink, 2008: Hurricanes and the physics of surges. Phys. Today, 61, 33-38.

Ris, R. C., L. H. Holthuijsen, and N. Booij, 1999: A third-generation wave model for coastal regions. 2. Verification. J. Geophys. Res., 104, 7667-7681.

Rogers, W. E., P. A. Hwang, and D. W. Wang, 2003: Investigation of wave growth and decay in the SWAN model: Three regionalscale applications. J. Phys. Oceanogr., 33, 366-389.

Sheremet, A., and G. W. Stone, 2003: Observations of nearshore wave dissipation over muddy sea beds. J. Geophys. Res., 108, 3357, doi:10.1029/2003JC001885.

SiadatMousavi, S. M., F. Jose, and G. W. Stone, 2009: Simulating Hurricane Gustav and Ike wave fields along the Louisiana inner shelf: Implementation of an unstructured third-generation wave model, SWAN. Proc. Oceans 2009 Conf., Biloxi, MS, IEEE, 873-880.
Smith, J. M., 2000: Benchmark tests of STWAVE. Proc. Sixth Int. Workshop on Wave Hindcasting and Forecasting, Monterey, CA, Environment Canada, 369-379.

_ 2007: Full-plane STWAVE: II. Model overview. U.S. Army Engineer Research and Development Center, Vicksburg, MS, Rep. ERDC TN-SWWRP-07-5, 15 pp. [Available online at http://www.dtic.mil/cgi-bin/GetTRDoc?Location=U2\&doc= GetTRDoc.pdf\&AD=ADA471582.]

— - A. R. Sherlock, and D. T. Resio, 2001: STWAVE: Steadystate spectral wave model user's manual for STWAVE, version 3.0. USACE, Engineer Research and Development Center, Vicksburg, MS, Tech. Rep. ERDC/CHL SR-01-1, 81 pp.

— , R. E. Jensen, A. B. Kennedy, J. C. Dietrich, and J. J. Westerink, 2011: Waves in wetlands: Hurricane Gustav. Proc. 32nd Int. Conf. on Coastal Engineering. [Available online at https://journals.tdl.org/ICCE/article/view/1027.]

Snyder, R. L., F. W. Dobson, J. A. Elliott, and R. B. Long, 1981: Array measurements of atmospheric pressure fluctuations above surface gravity waves. J. Fluid Mech., 102, 1-59.

Uhlhorn, E. W., P. G. Black, J. L. Franklin, M. Goodberlet, J. Carswell, and A. S. Goldstein, 2007: Hurricane surface wind measurements from an operational stepped frequency microwave radiometer. Mon. Wea. Rev., 135, 3070-3085.

USACE, 1963: Interim survey report, Morgan City, Louisiana and vicinity. Rep. 63, U.S. Army Engineer District, New Orleans, LA, $166 \mathrm{pp}$.

_ 2009: Hydraulics and hydrology appendix. Louisiana Coastal Protection and Restoration: Final Technical Report, U.S. Army Engineer District, New Orleans, LA, 389 pp.

Vickery, P. J., D. Wadhera, M. D. Powell, and Y. Chen, 2009: A hurricane boundary layer and wind field model for use in engineering applications. J. Appl. Meteor. Climatol., 48, 381-405.

Westerink, J. J., and Coauthors, 2008: A basin- to channel-scale unstructured grid hurricane storm surge model applied to southern Louisiana. Mon. Wea. Rev., 136, 833-864.

Zijlema, M., 2010: Computation of wind-wave spectra in coastal waters with SWAN on unstructured grids. Coastal Eng., 57, 267-277. 